\title{
Deletion of the low-molecular-weight glutenin subunit allele Glu-A3a of wheat (Triticum aestivum L.) significantly reduces dough strength and breadmaking quality
}

Shoumin Zhen, Caixia Han , Chaoying Ma, Aiqin Gu, Ming Zhang, Xixi Shen, Xiaohui Li and Yueming Yan*

\begin{abstract}
Background: Low-molecular-weight glutenin subunits (LMW-GS), encoded by Glu-3 complex loci in hexaploid wheat, play important roles in the processing quality of wheat flour. To date, the molecular characteristics and effects on dough quality of individual Glu-3 alleles and their encoding proteins have been poorly studied. We used a Glu-A3 deletion line of the Chinese Spring (CS-n) wheat variety to conduct the first comprehensive study on the molecular characteristics and functional properties of the LMW-GS allele G/u-A3a.

Results: The Glu-A3a allele at the Glu-A3 locus in CS and its deletion in CS-n were identified and characterized by proteome and molecular marker methods. The deletion of Glu-A3a had no significant influence on plant morphological and yield traits, but significantly reduced the dough strength and breadmaking quality compared to CS. The complete sequence of the Glu-A3a allele was cloned and characterized, which was found to encode a B-subunit with longer repetitive domains and an increased number of a-helices. The Glu-A3a-encoded B-subunit showed a higher expression level and accumulation rate during grain development. These characteristics of the Glu-A3a allele could contribute to achieving superior gluten quality and demonstrate its potential application to wheat quality improvement. Furthermore, an allele-specific polymerase chain reaction (AS-PCR) marker for the Glu-A3a allele was developed and validated using different bread wheat cultivars, including near-isogenic lines (NILs) and recombinant inbred lines (RILs), which could be used as an effective molecular marker for gluten quality improvement through marker-assisted selection.
\end{abstract}

Conclusions: This work demonstrated that the LMW-GS allele Glu-A3a encodes a specific LMW-i type B-subunit that significantly affects wheat dough strength and breadmaking quality. The Glu-A3a-encoded B-subunit has a long repetitive domain and more a-helix structures as well as a higher expression level and accumulation rate during grain development, which could facilitate the formation of wheat with a stronger dough structure and superior breadmaking quality.

Keywords: Wheat, Glu-A3a, Molecular cloning, Dough strength, Breadmaking quality

\footnotetext{
* Correspondence: yanym@cnu.edu.cn

Equal contributors

Laboratory of Molecular Genetics and Proteomics, College of Life Science,

Capital Normal University, 100048 Beijing, China
}

() Biomed Central
2014 Zhen et al.; licensee BioMed Central. This is an Open Access article distributed under the terms of the Creative Commons Attribution License (http://creativecommons.org/licenses/by/4.0), which permits unrestricted use, distribution, and reproduction in any medium, provided the original work is properly credited. The Creative Commons Public Domain Dedication waiver (http://creativecommons.org/publicdomain/zero/1.0/) applies to the data made available in this article, unless otherwise stated. 


\section{Background}

Wheat (Triticum aestivum L., $2 \mathrm{n}=6 \mathrm{x}=42$, AABBDD), as a complex allohexaploid species, is one of the most important crops widely cultivated across the world. Wheat grains contain about $1015 \%$ proteins, and are one of the richest protein sources in the human diet. It is well known that wheat breadmaking quality is largely determined by the seed storage proteins present in the grain endosperm, which mainly consist of polymeric glutenins and monomeric gliadins [1,2]. The polymeric glutenins are further subdivided into high-molecular weight glutenin subunits (HMW-GS) and low-molecular-weight glutenin subunits (LMW-GS) according to their mobilities on a sodium dodecyl sulfate-polyacrylamide gel electrophoresis (SDS-PAGE) gel, which determine their dough elasticity, viscosity, and strength [2,3].

LMW-GS can be separated into three groups, the B, $\mathrm{C}$, and D subunits, based on their electrophoretic mobilities on an SDS-PAGE gel. Genetic analysis showed that these subunits are encoded by the Glu-A3, Glu-B3, and Glu-D3 loci on the short arms of the chromosomes 1A, $1 \mathrm{~B}$, and $1 \mathrm{D}$, respectively $[4,5]$. Some components were also found to be encoded by genes on the short arms of the group 6 and 7D chromosomes [6]. Based on their Nterminal amino acid sequences, LMW-GS are classified into three subclasses, LMW-m, LMW-s, and LMW-i types, according to the first amino acid residue of the mature protein: methionine, serine, and isoleucine, respectively [6]. The LMW-s type subunit seems to be predominant $[7,8]$. Typically, the N-terminal amino acid sequence is SHIPGLin LMW-s type subunits, while LMW-m type subunits have various N-terminal sequences such as METSHIGPL-, METSRIPGL-, and METSCIPGL- [9-11]. The LMW-i type subunit, first reported by Pitts et al. [12], lacks the Nterminal domain and starts directly with the repetitive region of ISQQQQ- after the signal peptide. Although the typical N-terminal domain is absent, LMW-i type subunits can be expressed normally, similar to LMW-m and LMW$\mathrm{s}$, in the wheat endosperm [13,14]. Most LMW-GSs possess eight cysteine residues, although their positions vary in the different types of subunits, which plays important roles in the formation of intra- and inter-molecular disulfide bonds in the gluten macropolymer [14].

Compared to the Glu-1 loci encoding HMW-GS, Glu-3 loci exhibit more extensive allelic variations that are closely related to gluten quality. Early work by Gupta and Shepherd [15] identified and named six alleles at Glu-A3, nine alleles at Glu-B3, and five alleles at Glu-D3 loci in common wheat. Recently, 14 unique LMW-GS genes in the wheat cultivar Xiaoyan 54 were identified, four of which were located at Glu-A3, three at Glu-B3, and seven at Glu-D3, based on bacterial artificial chromosome (BAC) library screening and proteomics analysis [16]. The results from a set of Aroona LMW-GS near isogenic lines
(NILs) showed that the Glu-A3 locus has two m-type and 24 i-type genes [17]. Analysis of the micro-core collections (MCC) of Chinese wheat germplasm identified more than 15 LMW-GS genes from individual MCC accessions, 46 of which were located at the Glu-A3 locus [18].

Since extensive allelic variations are present at Glu-3 loci, it is generally difficult to accurately determine the functional properties of individual alleles in different genotypes. To date, the main method used to investigate the effects of different Glu-3 alleles on dough quality has involved determination of their effects and ranks in NILs. Earlier research on the durum wheat NILs Lira 42 and Lira 45 showed that the LMW-2 type subunit in Lira 45 had significantly greater beneficial effects on gluten strength and breadmaking quality than the LMW-1 subunit in Lira 42 [19]. In bread wheat, Glu-A3d possesses three active LMW-GS genes and produces the highest Zeleny sedimentation value (ZSV) and Extensograph maximum resistance $\left(\mathrm{R}_{\max }\right)$ [17]. Other reports also showed that the Glu-A3d allele had a superior effect on dough strength [20-22]. Recent work on a set of Aroona NILs showed that Glu-A3b contributed to a longer midline peak time (MPT) and better raw white Chinese noodle (RWCN) color [23]. Despite the large number of studies performed on the functions of Glu-3 alleles, more comprehensive and in-depth analyses on the structures and functions of the individual alleles at Glu-3 loci are still lacking.

In the current work, we conducted the first comprehensive investigation on the molecular characteristics and functional properties of the LMW-GS allele Glu-A3a by using a Glu-A3 deletion line in the Chinese Spring (CS) wheat cultivar in combination with various proteomics and molecular biology approaches. Our results demonstrate that the deletion of Glu-A3a significantly reduces wheat dough strength and breadmaking quality. In addition, we demonstrated that Glu-A3a results in a longer repetitive domain and more $\alpha$-helices in the encoded subunit, as well as a higher expression level and accumulation rate during grain development, which could help to improve the formation of a stronger dough structure and superior quality.

\section{Results}

Identification and characterization of seed proteins in CS and the Glu-A3 deletion line CS-n

A Glu-3 deletion line of CS was screened and developed in our laboratory, and named CS-n. Compared to CS, the morphological characteristics of plants, spikes, and seeds, as well as the growth and development traits of CS-n showed no significant differences (Additional file 1: Figure S1, Additional file 2: Figure S2, and Additional file 3: Table S1). The grain protein compositions of CS and CS- $n$ were identified by using various proteome approaches 
(Figure 1 and Additional file 4: Figure S3). The results indicated that CS-n showed the same albumin and globulin compositions as CS, while gliadins displayed minor differences between CS- $n$ and CS; only one gliadin band obtained by acidic polyacrylamide gel electrophoresis (A-PAGE) was absent in CS-n (Additional file 4: Figure S3).

Glutenin subunits identified by SDS-PAGE indicated that HMW-GS in CS-n were the same as those in CS $(\mathrm{N}, 7+8$, $2+12$ ), and most LMW-GS bands were also identical, except that one clear B-type LMW-GS encoded by Glu-A3a was absent in CS-n (Figure 1a). Two-dimensional electrophoresis (2-DE) analysis revealed that Glu-A3a encodes two proteins (spots 1 and 2 in Figure 1b), which were further determined to be one LMW-i type subunit by liquid chromatography-tandem mass spectrometry (LC-MS/MS), as shown in Table 1. Reversed-phase ultra-performance liquid chromatography (RP-UPLC) analysis further confirmed that Glu-A3a encodes two protein components (peaks 1 and 2 in Figure 1c), which were eluted at $15.5 \mathrm{~min}$ and $16 \mathrm{~min}$, respectively. Both peaks accounted for $22.58 \%$ of the total LMW-GS in CS.

To obtain the accurate molecular mass of the Glu$A 3 a$-encoded B-subunit, the expected protein band on the SDS-PAGE gel indicated in Figure 1a was collected and then analyzed by matrix-assisted laser desorption/ ionization time-of-flight mass spectrometry (MALDITOF-MS). As shown in Additional file 5: Figure S4, the Glu-A3a-encoded LMW-GS B-subunit was easily identified, and its molecular mass was determined to be 41,701.2 Da.

\section{Confirmation of Glu-A3a deletion in CS-n with a sequence-tagged site polymerase chain reaction (STS-PCR) marker}

To further confirm the deletion of the Glu-A3 locus in CS-n, a pair of STS primers developed from the single nucleotide polymorphisms (SNPs) in Glu-A3 allelic variants [24] were used to amplify the Glu-A3a gene. As shown in Figure 2, one specific PCR product of 529 bp was amplified in CS, the CS-1S $1 / 1 \mathrm{~B}$ substitution line, the CS- $1 S^{1}$ addition line, and Aroona, which contain the Glu-A3a allele, whereas no such fragments were obtained in the other materials without Glu-A3a, such as CS-n. The specific amplified 529-bp fragment was sequenced, and the sequence was the same as those from the upstream $140395 \mathrm{bp}$ of the Glu-A3a-coding sequence shown in Additional file 6: Figure S5. Thus, these results confirmed that the Glu-A3 locus was deleted in CS-n.

\section{Comparison of gluten quality properties between CS-n and CS}

Dough strength and breadmaking quality testing showed that the main gluten quality parameters in CS- $n$ were significantly reduced compared to those of CS (Tables 2 and 3). In general, flour yield, water absorption, final viscosity, and peak viscosity between CS-n and CS showed no apparent differences. However, deletion of Glu-A3a in CS- $n$ increased the ash content by $15.39 \%$. Ash content is an important indicator of flour quality, which has a moderately negative effect on noodle color [25]. In addition, the deletion of Glu-A3a in CS-n resulted in a significant decrease of the gluten index (4\% reduction) and an increase in the flour falling number $(5.05 \%$ increase), as shown in Table 1. The gluten index was shown to have a positive relationship with strong dough property [26].

Farinograph analysis indicated that development time, stability time, tolerance index, and farinograph quality number in CS-n were significantly lower than those in CS (Table 2). These properties led to a decrease in loaf volume of CS-n from 760 to $735 \mathrm{~cm}^{3}$ (Table 2 and Figure 3). Bread texture analysis showed that the hardness and

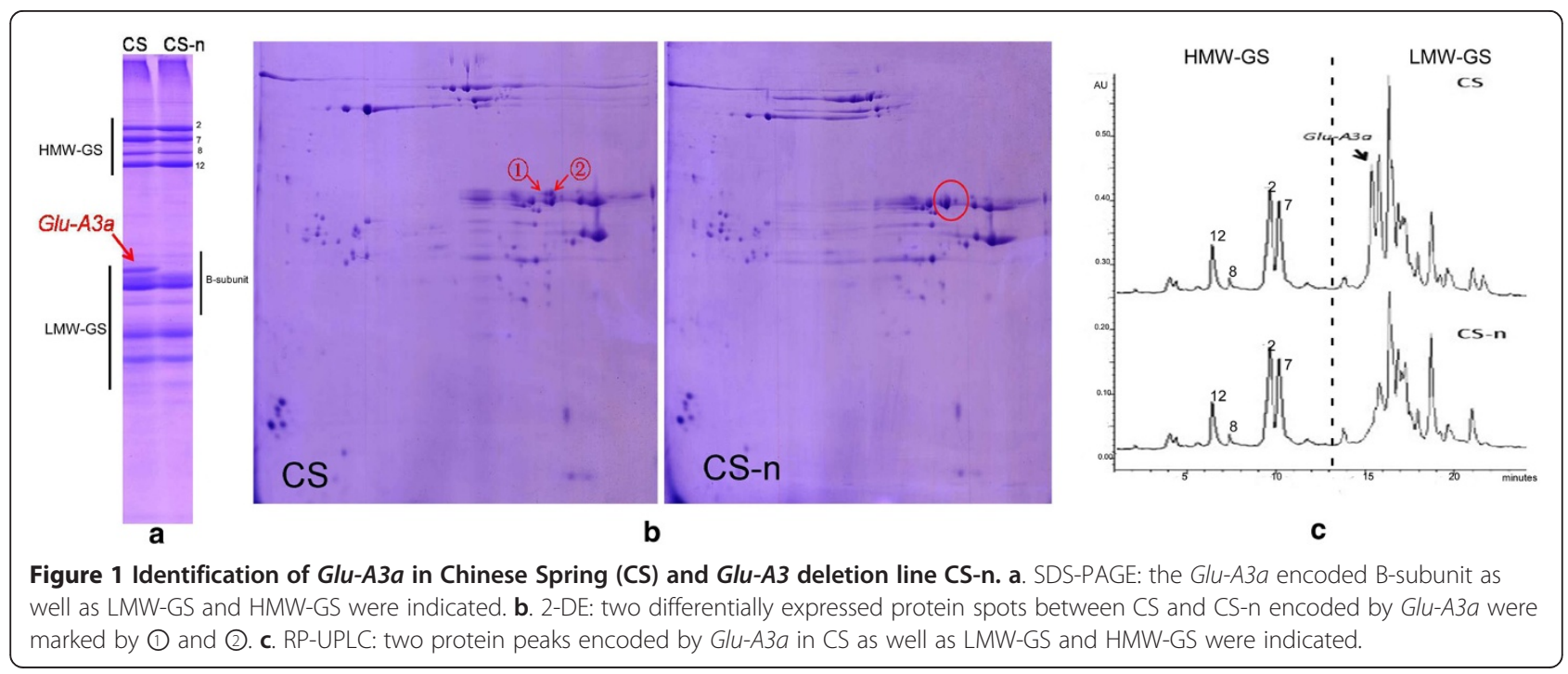


Table 1 LC-MS/MS analyses of peptides obtained after tryptic digestion of the isolated spot and bands

\begin{tabular}{lllll}
\hline $\begin{array}{l}\text { Protein } \\
\text { origin }\end{array}$ & Identified sequences & $\begin{array}{l}\text { Unique } \\
\text { PepCount }\end{array}$ & Start & Stop \\
\hline $\begin{array}{lllll}\text { Prokaryotic } \\
\text { expression }\end{array}$ & VFLQQQCIPVAM & 1735.0381 & 194 & 205 \\
& VFLQQQCIPVAMQR & 1719.0387 & 194 & 207 \\
& SQMLQQSICHVMQQQCCQQLR & 2693.0386 & 212 & 232 \\
SDS-PAGE & VFLQQQCIPVAMQR & 1735.0381 & 194 & 205 \\
2-DE spots & MKTFLVFALLALAAA & 1735.9338 & 1 & 15 \\
& VFLQQQCIPVAMQR & 1733.9270 & 214 & 227 \\
& QIPEQSRHESIR & 1479.7839 & 253 & 264 \\
& QIPEQSR & 857.4691 & 253 & 259 \\
& TLPTMCSVNVPLYETTTSVPLGGI & 2649.4285 & 347 & 371 \\
\hline
\end{tabular}

resilience of bread in CS were superior to those in CS$n$. Further cell size analysis of the bread demonstrated that the quality in CS-n was significantly reduced (Table 3). For example, wrapper length, slice brightness, and wall thickness of CS- $n$ bread slices were much lower than those of CS. The cell diameter and elongation in CS-n were also reduced as a result of Glu-A3a deletion.

\section{Molecular characteristics of the LMW-GS allele Glu-A3a}

To further understand the molecular mechanisms underlying the significant effects of Glu-A3a on gluten and breadmaking quality, the complete coding sequence of Glu-A3a was amplified and sequenced by allelicspecific (AS) PCR. Based on the previously characterized Glu-A3 genes, a pair of specific primers (A3-F and A3$\mathrm{R})$ for the Glu-A3 locus was designed and used to amplify the Glu-A3a allele from CS. As shown in Additional file 7: Figure S6, a single band of approximately $1100 \mathrm{bp}$ was obtained from CS, whereas no product was amplified from CS-n. Since most of the complete coding sequences of LMW-GS genes vary in length between 909 and 1167 bp [6,27-29], the size of the amplified band corresponded well to the known LMW-GS gene sizes.

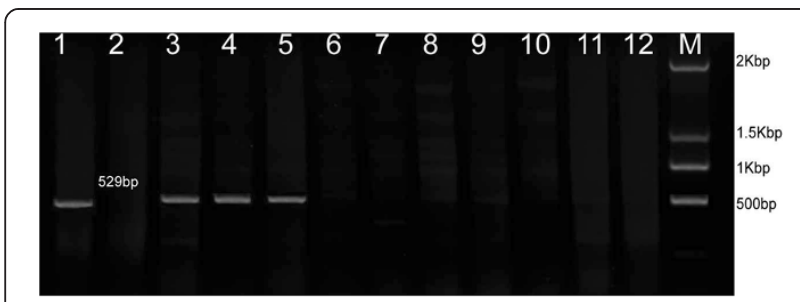

Figure 2 Identification of Glu-A3a by STS-PCR markers. 1. CS (Glu-A3a), 2. CS-n; 3. CS-1S'/1B; 4. CS 1S' addition line; 5. Aroona-A3a (Glu-A3a); 6. Aroona-A3b (Glu-A3b); 7. Aroona (Glu-A3C); 8. Aroona-A3d (Glu-A3d); 9. Aroona-A3e (Glu-A3e); 10. Aroona-A3f (Glu-A3f); 11. Glenlea (Glu-A3g); 12. CB037A. M. molecular mass marker: 2000 bp, 1500 bp, $1000 \mathrm{bp}$ and $500 \mathrm{bp}$. Glu-A3a fragment with $529 \mathrm{bp}$ was arrowed.
After sequencing of the amplified product, a complete open reading frame of $1134 \mathrm{bp}$ was obtained. Sequence alignment showed that the cloned gene had no internal stop codons and contained typical structural features of LMW-GS, and therefore was named as Glu-A3a (Additional file 7: Figure S6). After searching the GenBank database, we found that the cloned Glu-A3a gene had the same sequence as GluA3-11 from cultivar Aroona-A3a (GenBank accession number FJ549928). The deduced amino acid sequence of Glu-A3a showed the presence of an isoleucine as the first amino acid residue in the $\mathrm{N}$-terminal of the mature protein, indicating that it belongs to the LMW-i type subunit [6].

The complete coding sequence of Glu-A3a was aligned with 15 other known LMW-i type genes to detect SNP and insertion/deletion (InDel) variations, and the results are listed in Table 4. These LMW-i genes originated from different Triticum species, including $T$. aestivum and T. dicoccoides. Six SNPs at different positions, resulting from G-A or C-T transitions and two deletions at nucleotides 81 and 854, were identified in GluA3a. Six SNPs could produce amino acid substitutions, and thus are considered nonsynonymous SNPs.

The deduced amino acid sequence of Glu-A3a had 376 amino acid residues with a predicted molecular mass of $41,346.1 \mathrm{Da}$, corresponding well to that determined by MALDI-TOF-MS (41,701.2 Da). Multiple alignment of the deduced amino acid sequences of Glu$A 3 a$ with the other 14 LMW-i type subunits (Figure 4) showed that all have conserved signal peptides and four domains in the mature protein sequences, including a repetitive domain, cysteine-rich region, glutamine-rich region, and C-terminal conservative region, as reported by Cassidy et al. [27]. Similar to other LMW-i type subunits, the Glu-A3a-encoded subunit contained eight cysteine residues at relatively conserved positions (Additional file 8: Table S2). It is speculated that the first and seventh cysteines of the LMW-GS form the inter-molecular disulfide bond, while the rest form three intra-molecular disulfide bonds [30,31].

The number of repeats present in the repetitive domain is mainly responsible for the length variation and the general hydrophilic character of LMW-GS [30]. The Glu-A3a-encoded subunit contained the typical repeat motif of LMW-GS: $P_{1}{ }_{2} \mathrm{FP} / \mathrm{SQ}_{2}$ 6. Our results showed that Glu-A3a has a rather large and regular repeated sequence domain that includes a high proportion of glutamine residues (about 46\%) in the repeats (consensus sequence PPFSQQQQ), and two polyglutamine stretches with 11 and 12 continuous glutamine residues in the repetitive and C-terminal domains, respectively. Repeat motif numbers in LMW-i subunits are much higher than those in the LMW-m and LMW-s subunits, ranking them the longest protein subunits among all Glu-3 loci. 
Table 2 Quality parameters of dough and bread slices in CS and CS-n

\begin{tabular}{|c|c|c|c|c|c|c|c|c|c|}
\hline \multirow{2}{*}{$\begin{array}{l}\text { Materials } \\
\mathrm{CS}\end{array}$} & \multirow{2}{*}{$\begin{array}{l}\text { Flour yield (\%) } \\
56.26\end{array}$} & \multirow{2}{*}{$\begin{array}{l}\text { Ash (\%) } \\
0.520 .01^{* *}\end{array}$} & Wet glutenin (\%) & Total protein (\%) & \multicolumn{2}{|c|}{ Water absorption } & \multicolumn{2}{|c|}{$\begin{array}{l}\text { Development } \\
\text { time (min) }\end{array}$} & \multirow[t]{2}{*}{ Stability (min) } \\
\hline & & & $50.80 .5^{*}$ & 17.74 & 560.1 & & $0.8^{* *}$ & 11.4 & \\
\hline CS-n & 55.14 & 0.610 .01 & 52.1 & 17.68 & 56.40 .1 & & .90 .4 & 9.3 & 0.9 \\
\hline Materials & $\begin{array}{l}\text { Tolerance } \\
\text { index (FU) }\end{array}$ & $\begin{array}{l}\text { Farinograph } \\
\text { quality number }\end{array}$ & LV $\left(\mathrm{cm}^{3}\right)$ & $\begin{array}{l}\mathrm{P} / \mathrm{L} \text { of Alveograph NC } \\
\text { Consistograph }\end{array}$ & NG Hardnes & (ce1) & $\begin{array}{l}\text { Resilie } \\
\text { (Area }\end{array}$ & $\begin{array}{l}\text { ce sec } \\
\text {-T) }\end{array}$ & $\begin{array}{l}\text { Attenuation } \\
\text { ratio }(2: 3)\end{array}$ \\
\hline CS & $1215^{*}$ & 5095 & $7705^{* *}$ & $.250 .005^{* *}$ & $528.46 .9^{*}$ & 7438.5 & 5326 & 64.020. & \\
\hline CS-n & 9512 & 48611 & 7352.5 & 0.350 & 56.8710 .3 & 7093.6 & 643 & 63.660 & \\
\hline
\end{tabular}

** significant difference $(P<0.001)$, *means difference $(P<0.05)$.

\section{Secondary structure and function prediction of the Glu-A3a-encoded protein}

The secondary structures of the Glu-A3a-encoded protein (FJ549928) and five other LMW-i type subunits from bread wheat (AY724436, AY724437, AY263369, AY831866, and AY542896) were predicted by the PSIPRED server, as shown in Table 5 . The results showed that the $\alpha$-helices and $\beta$-strands were dispersed in the normal configuration in C-terminal I and were highly conserved in C-terminal III. FJ549928 contained seven $\alpha$-helices, mainly located at the C-terminal, and one $\beta$-strand dispersed in the conserved $\mathrm{C}$-terminal region. Thus, the number of $\alpha$-helices in FJ549928 was much higher than that of the other five subunits, which contain only $03 \alpha$-helices. For example, the LMW-i type glutenin subunit AY542896, assigned to the $1 \mathrm{~A}$ chromosome, only has one $\alpha$-helix, which was confirmed to co-migrate with the LMW-50 subunit that plays an important role in determining good quality characteristics of Glenlea [13] and the XYGluD3-LMWGS1 subunit (AY263369), with only $3 \alpha$-helices, is also considered to have a positive effect on dough quality [37].

\section{Phylogenetic analysis of Glu-A3a and other LMW-GS genes}

A homology tree was constructed to reveal the phylogenetic relationships among 25 LMW-GS genes at Glu-3 loci from different species and genomes through nucleotide sequence alignment of their coding regions using MEGA5 software (Figure 5). These sequences comprised 21 LMWGS genes from different genomes of Triticum diploid, tetraploid, and hexaploid species. The phylogenetic tree displayed two clear branches, which corresponded well to distinguishing the LMW-i type from the LMW-m and LMW-s type subunits. This demonstrated that LMW-i type genes have undergone greater divergence during evolution compared to LMW-s and LMW-m genes, as previously reported [38,39]. Sine LMW-m and LMW-s type subunit genes generally show higher consistency, they showed close phylogenetic evolutionary relationships. Glu-A3a showed a closer relationship with other LMW-i type genes from common wheat. All of the LMW-i type subunit genes from common wheat and related species shared higher sequence identity, indicating their high evolutionary conservation.

\section{Heterologous expression of Glu-A3a in Escherichia coli and determination of the corresponding native protein encoded by Glu-A3a}

The Glu-A3a-coding region without signal peptides was expressed in $E$. coli. The expressed fusion protein was separated by both SDS-PAGE and 2-DE, and was further identified by LC-MS/MS. SDS-PAGE identification (Figure 6a) indicated that the relative mobility of the expressed protein was the same as that of the native Glu-A3a-encoded subunit of CS, confirming that Glu-A3a without the $\mathrm{N}$-terminus can be expressed normally, similar to other LMW-i type genes [13]. Furthermore, 2-DE separation of the expressed protein (Figure 6b) demonstrated a similar pattern as that shown in Figure 1b. LCMS/MS identification also confirmed that the expressed protein was the Glu-A3a-encoded subunit present in CS, as revealed by the previous tandem MS results (Table 1).

To verify the authenticity of the cloned sequence, LCMS/MS was conducted by using the native Glu-A3a subunit digested by trypsin. We compared the results of LC-MS/MS of the SDS-PAGE band of CS, the heterologous protein, 2-DE spots, and the amino acid sequence of the Glu-A3a gene. This gives a coverage rate of $18.26 \%$

Table 3 Comparison of C-cell parameters of bread slices between CS and CS-n

\begin{tabular}{|c|c|c|c|c|c|c|c|c|c|c|c|c|c|c|}
\hline Materials & $\begin{array}{l}\text { Wrapper } \\
\text { length }\end{array}$ & $\begin{array}{l}\text { Slice } \\
\text { brightness }\end{array}$ & $\begin{array}{l}\text { Cell } \\
\text { contrast }\end{array}$ & & $\begin{array}{l}\text { Num } \\
\text { of ce }\end{array}$ & $\begin{array}{l}\text { nber } \\
\text { ells }\end{array}$ & $\begin{array}{l}\text { Cell } \\
\text { density }\end{array}$ & $\begin{array}{l}\text { Wall } \\
\text { thickness }\end{array}$ & $\begin{array}{l}\text { Cell } \\
\text { diameter }\end{array}$ & $\begin{array}{l}\text { Coarse/Fin } \\
\text { clustering }\end{array}$ & & $\begin{array}{l}\text { Avera } \\
\text { elong }\end{array}$ & $\begin{array}{l}\text { e cell } \\
\text { tion }\end{array}$ & $\begin{array}{l}\text { Net cell } \\
\text { elongation }\end{array}$ \\
\hline CS & $19104^{* *}$ & 140.51 .8 & 0.7470 .006 & 3163 & 323 & 0.01 & $\begin{array}{l}2178 \\
0.000138^{*}\end{array}$ & $3.20 .03^{*}$ & $15.510 .66^{*}$ & $\begin{array}{lll}0.102 & 0.018 \quad 1\end{array}$ & 1.78 & 30.01 & * & 1.330 .03 * \\
\hline CS-n & 18577 & 1370.4 & 0.7470 .001 & 3086 & 645 & 0.0 & $\begin{array}{l}2287 \\
0.000128\end{array}$ & 3.070 .04 & 14.270 .06 & $0.0770 .001 \quad 1$ & 1.70 & 0.02 & 1.23 & 0.04 \\
\hline
\end{tabular}

**Highly significant difference $(P<0.001)$, *Significant difference $(P<0.05)$. 


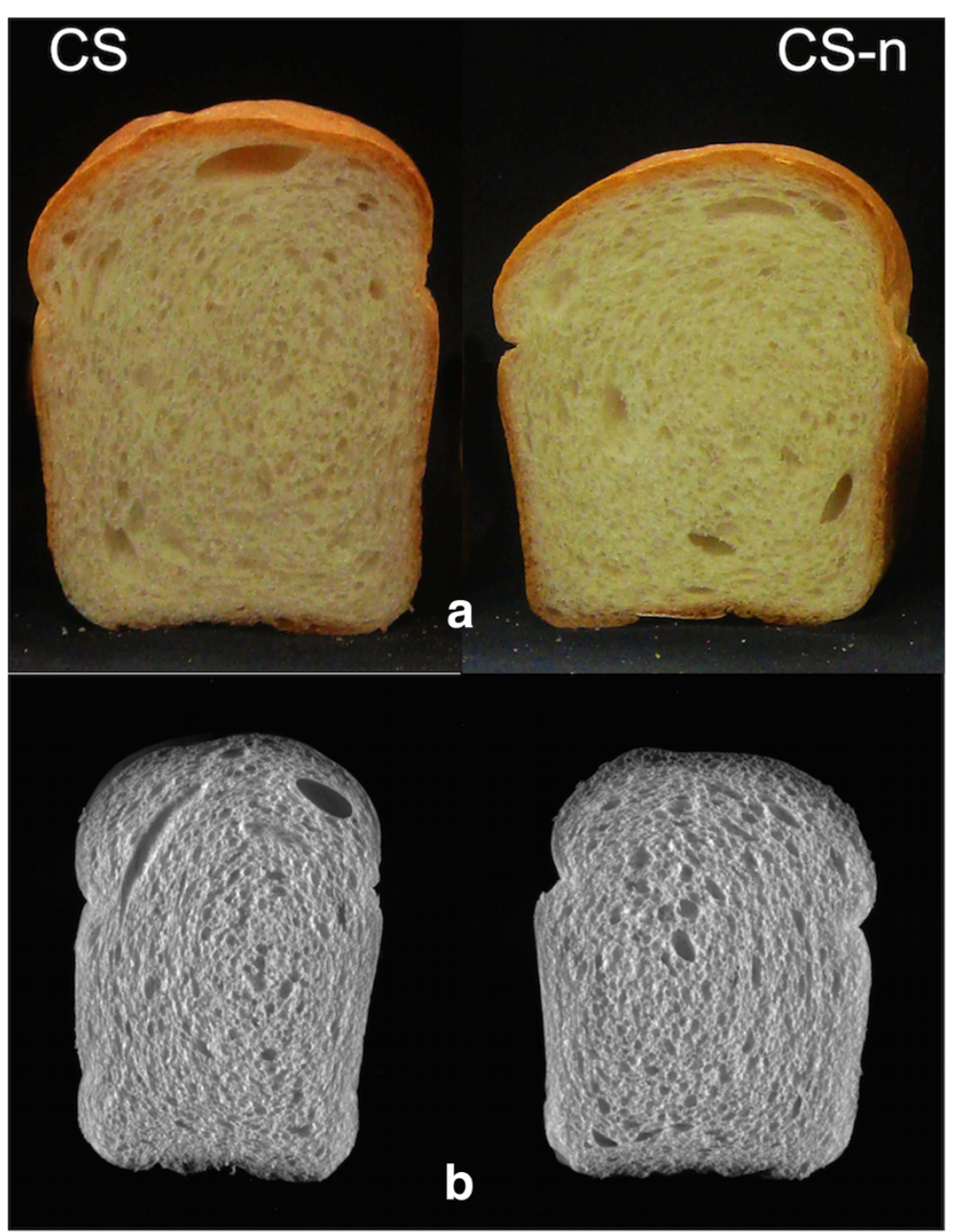

Figure 3 The loaves baking pictures and C-cell pictures of CS, CS-n. (a) The loaves baking pictures of CS and CS-n. (b) the C-cell pictures of CS and CS-n.

(65/356 amino acids of the mature polypeptide). These results revealed consistency in the peptide sequences among the samples, confirming the correspondence of the Glu$A 3 a$ gene and its native encoded subunit.

Dynamic expression profiles of the Glu-A3a gene and its encoded protein during grain development

The dynamic transcription expression profiles of the Glu-A3a gene at 5, 11, 14, 17, 20, 23, 26, and 29 days post anthesis (DPA) of grain development were detected by quantitative real-time (qRT)-PCR in both CS and CSn. Real-time melting temperature curves for the gene showed a single peak. qRT-PCR efficiency was determined by five serial five-fold dilutions of CDNA, and the standard curve confirmed high RT-PCR efficiency rates (Additional file 9: Figure S7). As shown in Figure 7a, the Glu-A3a gene displayed an up-down expression pattern during grain development of $C S$, with peak expression occurring at 14 DPA. However, Glu-A3a mRNA could not be detected in CS-n, further confirming the deletion of the Glu-A3 locus. SDS-PAGE analysis showed that the Glu-A3a-encoded B-subunit exhibited a gradual up-regulated expression pattern, and it began to rapidly accumulate after $11 \mathrm{DPA}$ (Figure 7b). At 5 DPA, no

Table 4 The positions of SNPs and InDels identified between Glu-A3 and other LMW-i type gene*

\begin{tabular}{|c|c|c|c|c|c|c|c|c|}
\hline LMW-GS & $81-103$ & 167 & 198 & 377 & 421 & 436 & 441 & 854 \\
\hline FJ594428 & - & $\mathrm{T}$ & $G$ & $\mathrm{~T}$ & $\mathrm{~T}$ & $C$ & $A$ & - \\
\hline Fifteen other LMW-i genes & CACCACCATITCGCAGCAACAACA & C & $A$ & C & $\mathrm{C} /-$ & T/- & - & G \\
\hline
\end{tabular}

*Horizontal dashes indicated the deletions of nucleotide. Other 15 LMW-i genes included: 453157, AY453158, AY453159, AY453160, AY542896, AY831863, AY831865, AY831866, DQ217661, EU189087, FJ549931, FJ549932, FJ549933, FJ549934, JQ417918. 


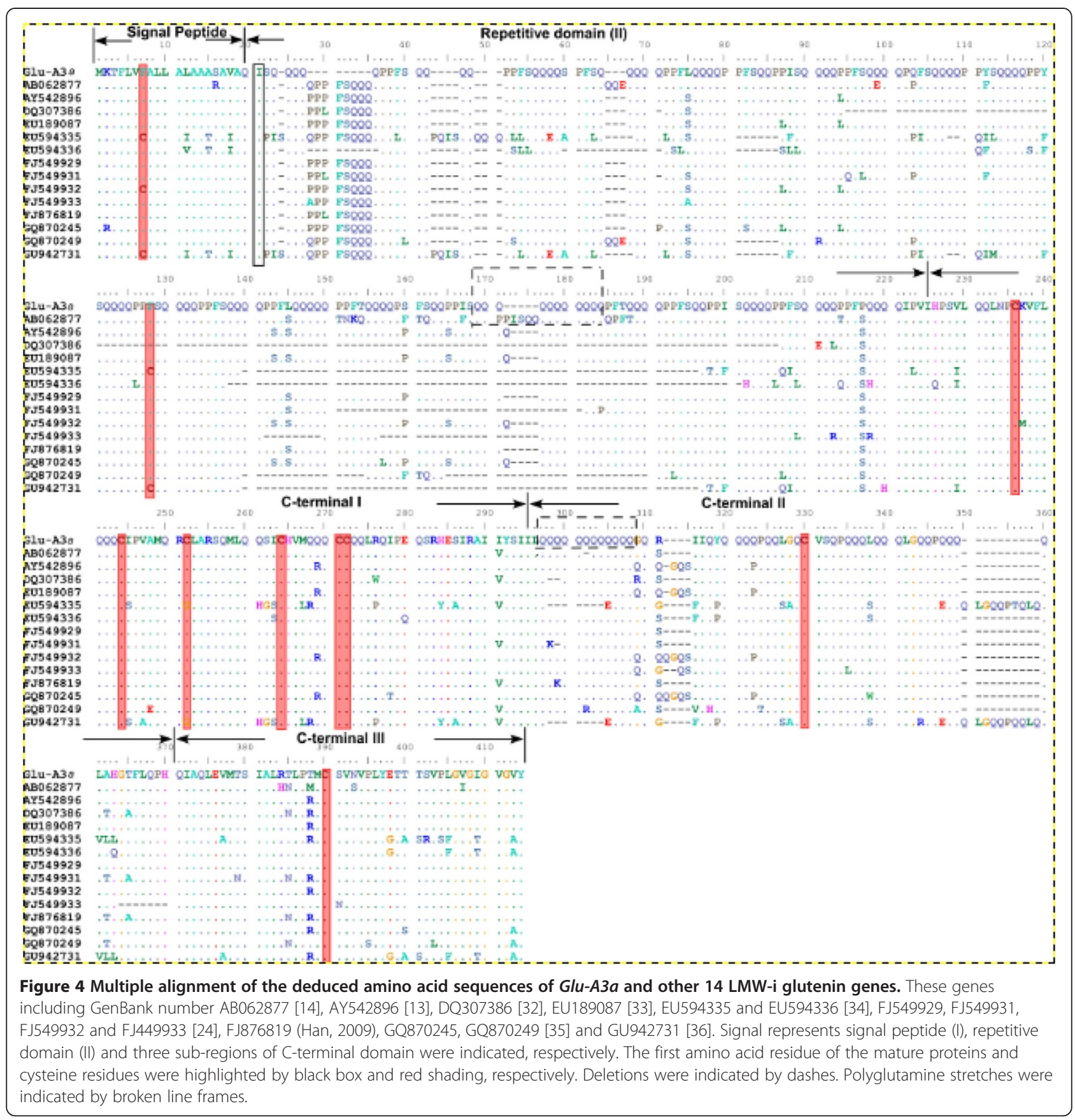

LWM-GS genes could be detected, and both LMW-GS and HMW-GS showed trace expression levels. After 14 DPA, the B-subunit as well as other LMW-GS and HMW-GS genes displayed significant up-regulation, and peak expression occurred at 17 DPA (Figure 7b).

\section{Development and validation of an SNP-based molecular marker for Glu-A3a}

An AS-PCR marker was developed based on the SNPs detected in Glu-A3 genes. A pair of specific primers for GluA3a (Glu-A3a F: GCAAAGAAGGAAAAGA GGTGG, R:
GGTTGTTGTTGTTGCTGCA) was designed and tested in different genotypes and hybrid generations with different Glu-A3 alleles. The materials with different Glu-A3 alleles included 48 bread wheat cultivars, the CS- $1 \mathrm{~S}^{\mathrm{l}} / 1 \mathrm{~B}$ substitution line, and the CS-1S $S^{1}$ addition line, as well as seven Aroona NILs and four recombinant inbred lines (RILs) derived from a cross between the CS substitution line CS-1S $/ 1 \mathrm{~B}$ with Glu-A3a and the bread wheat cultivar CB037A with Glu-A3c (Additional file 10: Table S3). The Glu-A3 allele compositions of all materials used were identified by SDS-PAGE (Figure 8a). The PCR results 
Table $\mathbf{5}$ The secondary structure prediction of the six deduced LMW-GS

\begin{tabular}{|c|c|c|c|c|c|c|c|c|}
\hline \multirow[t]{2}{*}{ LMW-GS } & \multirow{2}{*}{$\begin{array}{l}\text { Structure } \\
\text { motifs }\end{array}$} & \multirow{2}{*}{$\begin{array}{l}\text { Contents } \\
\text { (\%) }\end{array}$} & \multirow[t]{2}{*}{ Total } & \multicolumn{5}{|c|}{ Dispersal in every region } \\
\hline & & & & $\mathrm{N}$-terminal domain & Repetitive domain & C-ter domain I & C-ter domain II & C-ter domain III \\
\hline \multirow[t]{2}{*}{ AY724436 } & a-helix & - & - & - & - & - & - & - \\
\hline & $\beta$-strand & 1.32 & 2 & - & - & - & - & 2 \\
\hline \multirow[t]{2}{*}{ Y724437 } & a-helix & 10.51 & 3 & - & - & 2 & - & 1 \\
\hline & $\beta$-strand & 0.68 & 1 & - & - & - & - & 1 \\
\hline \multirow[t]{2}{*}{ AY263369 } & a-helix & 11.6 & 3 & - & - & 2 & - & 1 \\
\hline & $\beta$-strand & 1.4 & 2 & - & - & 1 & - & 1 \\
\hline \multirow[t]{2}{*}{ AY831866 } & a-helix & 5.98 & 3 & - & - & 2 & - & 1 \\
\hline & $\beta$-strand & 1.09 & 2 & - & - & - & 1 & 1 \\
\hline \multirow[t]{2}{*}{ AY542896 } & a-helix & 2.72 & 1 & - & - & - & - & 1 \\
\hline & $\beta$-strand & 1.09 & 2 & - & - & 1 & - & 1 \\
\hline \multirow[t]{2}{*}{ Glu-A3a } & a-helix & 15.87 & 7 & - & 1 & 5 & 1 & - \\
\hline & $\beta$-strand & 0.79 & 1 & - & - & - & - & 1 \\
\hline
\end{tabular}

showed that one specific PCR product of 507 bp was amplified in all cultivars with Glu-A3a (Figure $8 \mathrm{~b}$ ). To validate the effectiveness of the STS marker, seven NILs and four RILs with different Glu-A3 allele compositions were used for PCR amplification. The results showed that the 507-bp fragment could be specifically amplified in the lines with the Glu-A3a allele, whereas no any amplification products were obtained from the lines with other Glu-A3 alleles, including CS-n without the Glu-A3 locus. These results confirmed that the developed AS-PCR marker could be

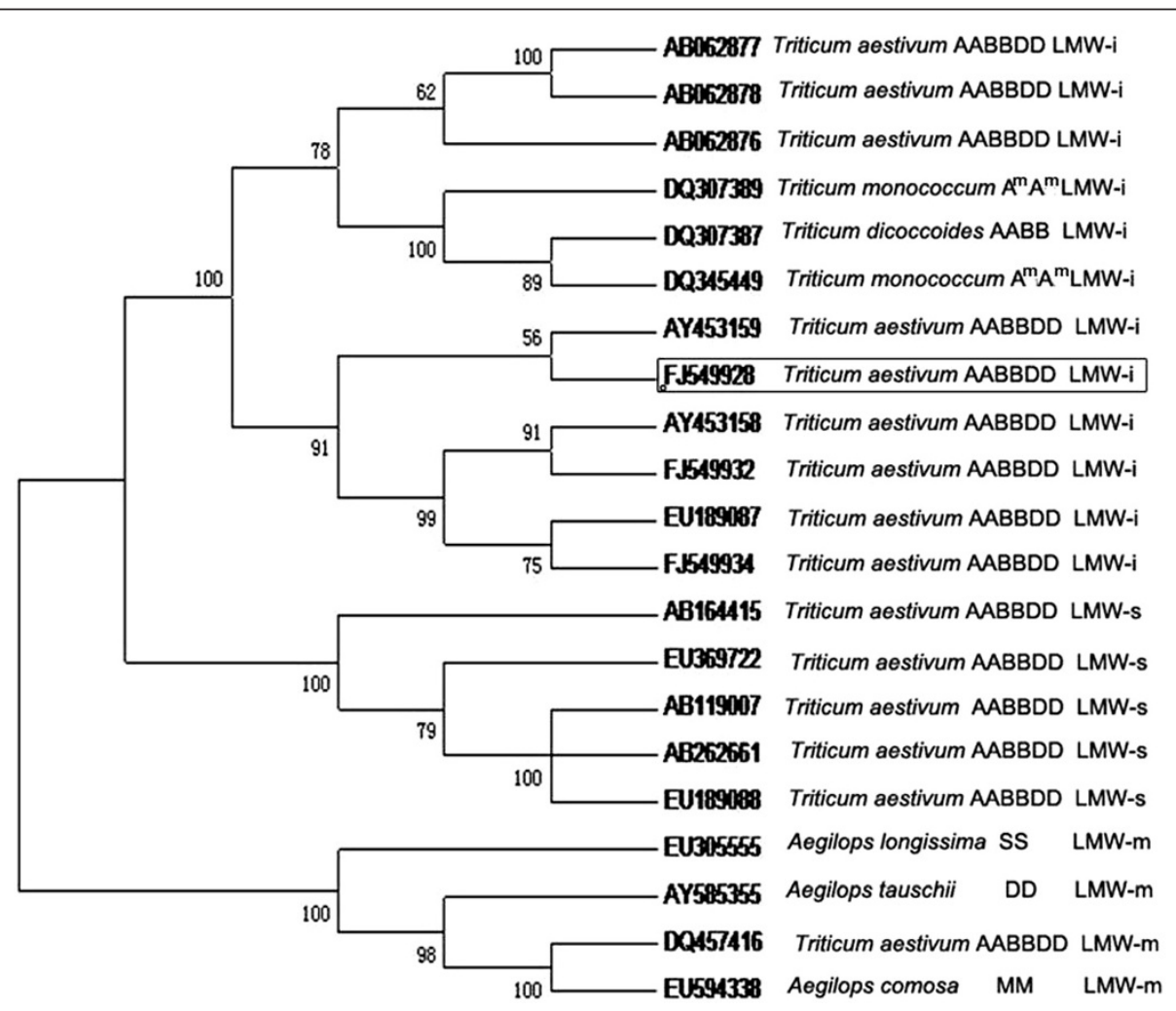

Figure 5 Homology tree constructed based on the coding regions of 21 LMW-GS genes. 21 LMW-GS genes named AB062876, AB062877 and AB062878 [14], AB262661 (Takeuchi T, 2006), AB1 19007 and AB164415 [40], AY453158 and AY453159 [41], AY585355 [42], DQ307389, DQ307387 and DQ345449 [39], DQ457416 [43], EU305555 [44], EU594338 [34], EU189087 and EU189088 [33], FJ549928, FJ549932 and FJ549934 [24]. The suffixes of GenBank accession numbers indicated the different types of the genes. Glu-A3a gene was circled by frame. 


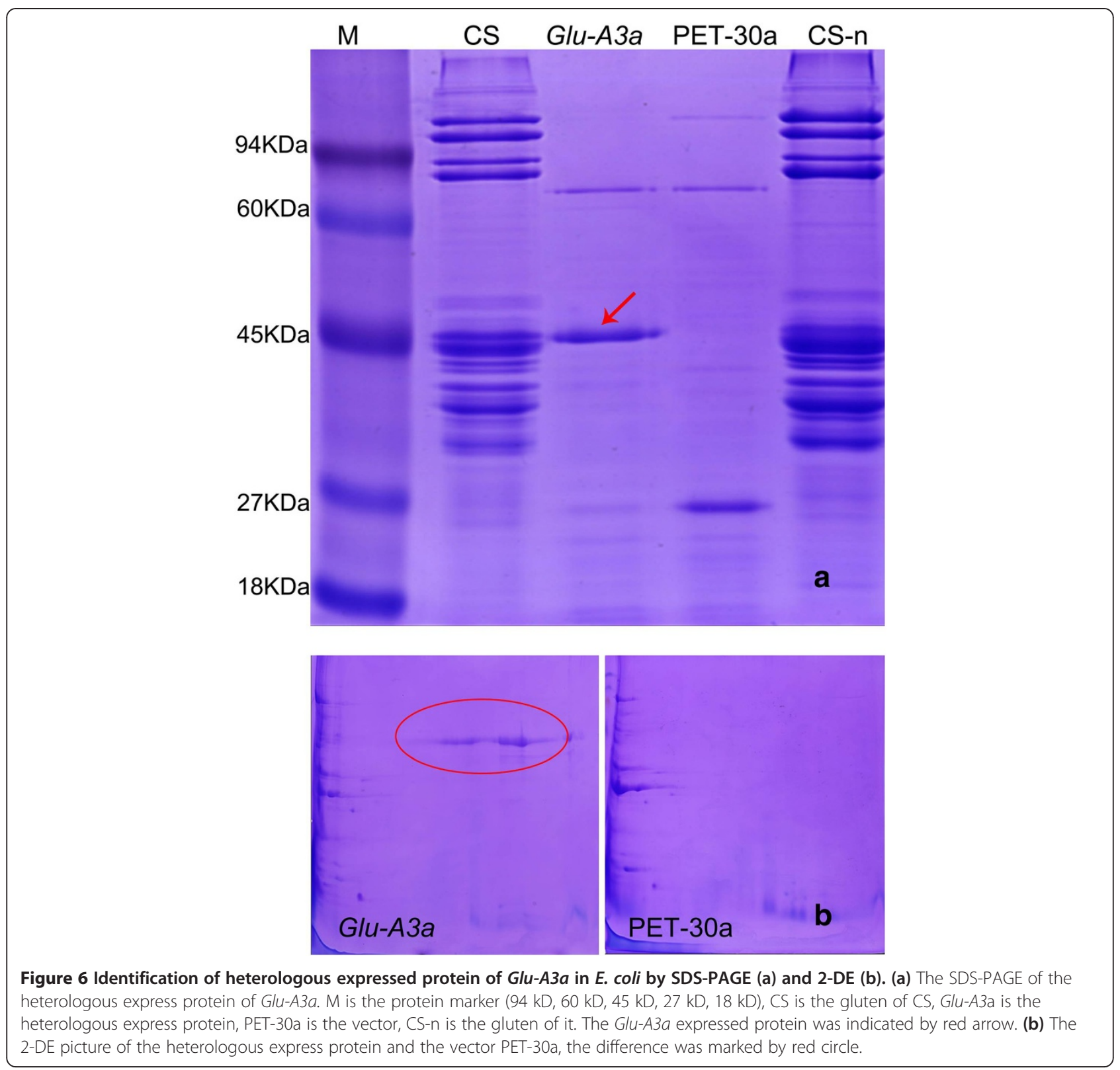

used as an effective tool for rapidly screening the Glu-A3a allele in wheat quality improvement strategies through molecular marker-assisted selection.

\section{Discussion}

In the present study, we performed a comprehensive survey on the molecular characteristics of Glu-A3a from a Glu-A3a-deletion line (CS-n), using proteomic and molecular biological methods. Here, we focus our discussion on the allelic variations at Glu-A3 loci, the structure and expression features of Glu-A3a, and molecular marker discovery and its potential application in wheat quality improvement.

\section{Allelic variations at Glu-3 loci and their effects on gluten quality}

LMW-GS account for approximately $60 \%$ of glutenin proteins in mature seeds and play important roles in the formation of glutenin macropolymer and gluten quality $[1,45]$, particularly for dough extensibility and strength [3-6,17]. LMW-GS genes belong to a multiple gene family and are found in multiple copies in Triticum aestivum; the copy number in hexaploid bread wheat was estimated to vary from 1015 [46] to 3540 [27,47]. A recent study based on BAC library screening and proteomics analysis showed that Glu-A3, Glu-B3, and Glu-D3 in the Chinese bread wheat cultivar Xiaoyan 54 contain 


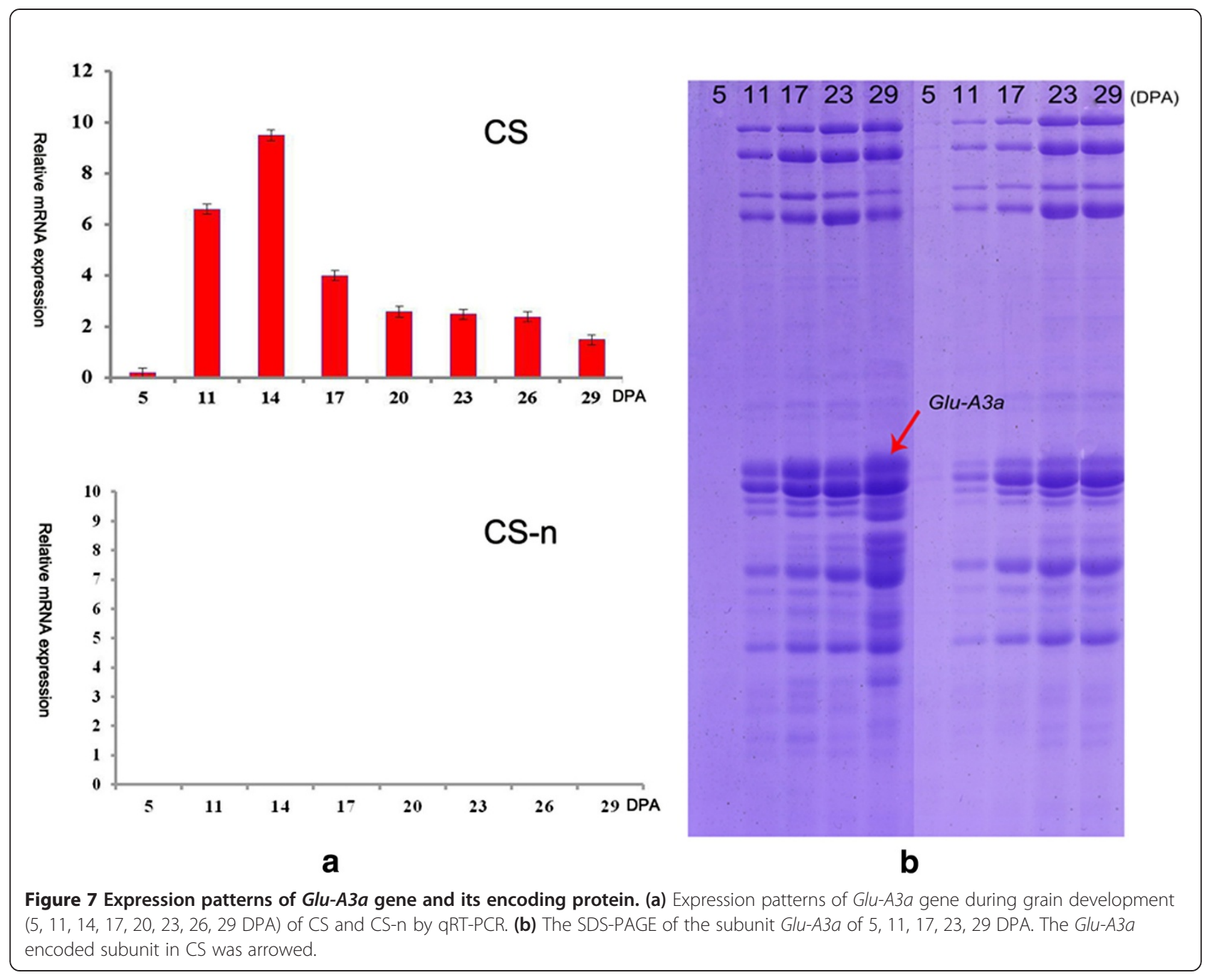

4, 3, and 7 genes, respectively [16]. In addition, by using the LMW-GS gene marker system, at least 15 LMW-GS genes were identified in Aroona NILs [17].

Glu-A3 and Glu-B3 alleles are known to play a major role in determining differences in processing qualities among the three Glu-3 loci, while Glu-D3 alleles play minor roles in determining quality variation in bread wheat [17]. In particular, the Glu-A3 locus was considered to have the biggest contribution to quality among all LMW-GS loci, in which Glu-A3f was found to have a strong positive effect on end-use quality [48]. In Australian wheat cultivars, LMW-GS provided better predictions of Rmax than HMW-GS [45]. The effects of different Glu3 alleles on Rmax showed the following ranking: Glu$A 3 b>$ Glu-A3d $>$ Glu-A3e $>$ Glu-A3c, Glu-B3i $>$ Glu-B3b $=$ Glu-B3a $>$ Glu-B3e = Glu-B3f = Glu-B3g = Glu-B3h $>$ Glu$B 3 c$, and Glu-D3e > Glu-D3b>Glu-D3a>Glu-D3c > Glu$D 3 d$ [17]. However, no studies of the effect of the Glu-A3a allele on gluten quality have been reported so far. In the present work, we found that the deletion of Glu-A3a significantly reduced dough strength and breadmaking quality, including most of the mixing and bread quality parameters (Tables 2 and 3). This indicates that Glu-A3a plays important roles in conferring high gluten quality to wheat.

\section{Molecular basis of the relationship between Glu-A3a and gluten quality}

The molecular structures of LMW-GS proteins play important roles in determining the dough strength and gluten quality; in particular, the distribution of cysteine residues could lead to functional protein differences [6]. The first and the seventh cysteines form the intermolecular disulfide bond, while the remaining cysteines form three intra-molecular disulfide bonds [11,30,31]. Thus, the number and position of cysteines are important to the formation of the secondary protein structure and, consequently, dough quality. The presence of a long repetitive domain is also considered to have a positive influence on wheat flour quality $[30,49]$. A repeated 


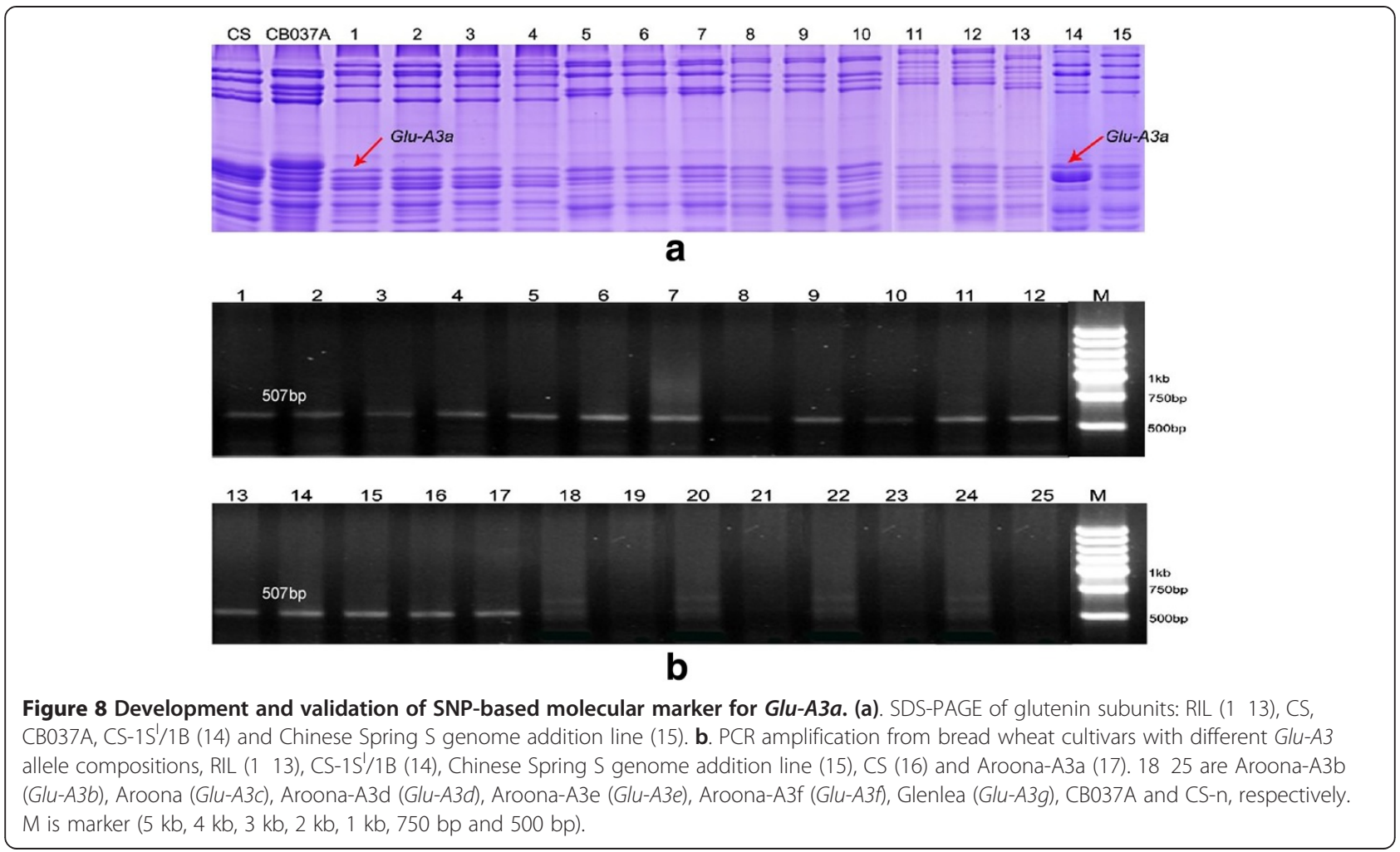

sequence domain could be helpful in increasing the viscosity and elasticity of the dough through increasing the inter-molecular interactions among the large number of glutamine side chains, which are both good hydrogen bond donors and acceptors [49-51]. According to Masci et al. [30], all the predicted $\alpha$-helices in the $42 \mathrm{~K}$ LMWGS seem to be located near the intra-molecular disulfide bonds. They also speculated that helix-helix interactions are involved in guiding the formation of the intramolecular disulfide bonds. Therefore, a higher $\alpha$-helix content may contribute to better quality of the dough [52]. The $\beta$-strands are generally considered to endow the protein with high elasticity and to improve the capability to resist distortion [38].

LMW-i type subunits contain eight highly conserved cysteine residues in the C-terminal domain (Table 5), which differ from the LMW-m and LMW-s subunits that have a cysteine residue in the $\mathrm{N}$-terminus or in the repetitive domain [39]. Therefore, the secondary structures of LMW-i subunits are expected to be quite different from those of the LMW-m and LMW-s subunits. Previous work on LMW-GS AY542896 and AY263369 indicated that they have positive effects on quality properties $[13,37]$. In the present study, comparative analysis with the secondary structures of AY542896 and AY263369 showed that the Glu-A3a-encoded subunit had more $\alpha$ helices (Table 4). The secondary structure is the foundation for a highly complex spatial conformation and is composed of structural motifs, including $\alpha$-helices, $\beta$ strands, and random coils. The higher $\alpha$-helix number in the Glu-A3a-encoded subunit could guide the formation of the intra-molecular disulfide bonds and contribute to superior dough strength and breadmaking quality.

The sizes of most of the cloned LMW-GS genes range from 900 to $1000 \mathrm{bp}$, and the gene LMW-TD22 with $1167 \mathrm{bp}$ is the longest complete gene among the cloned LMW-i genes analyzed to date [29]. The presence of a long repetitive domain is considered to have a positive influence on wheat flour quality because it can form more $\beta$-turns in the structure, thereby conferring elasticity to the protein molecule $[30,52]$. The molecular structure of the deduced LMW-TD22 subunit indicated a long repetitive domain of 21 repeat motifs (consensus sequence $\mathrm{P}_{1}{ }_{2} \mathrm{FP} / \mathrm{SQ}_{2}{ }_{6}$ ). In the present study, the GluA3a-encoded subunit was also found to have a long repeated sequence domain and a high proportion of glutamine residues (about 46\%), which could improve the conformation of superior gluten structure and breadmaking quality.

\section{Glu-A3a expression and LMW-GS synthesis}

It is well known that the expression levels as well as accumulation patterns of storage proteins are closely associated with gluten quality properties [53-55]. For example, the over-expressed HMW-GS $1 \mathrm{Bx}^{\mathrm{OE}}$ has positive effects on dough strength $[53,56]$. In addition, the 
accumulation rates vary between different groups of proteins, suggesting differential regulation of protein biosynthesis and different quality performance. In particular, the wheat biotype with superior HMW-GS $5+10$ subunits accumulated larger polymers more quickly than the biotype with poor allelic subunits $2+12$ [54].

The B-subunits of LMW-GS are the most abundant and have the greatest impact on wheat processing qualities [6]. In this work, RP-UPLC analysis revealed a higher expression level and greater proportion of Glu-A3a-encoded Bsubunits, accounting for more than $22 \%$ of the total LMW-GS in CS (Figure 1c), indicating its major contribution to LMW-GS synthesis and its important roles in determining dough quality. A recent study also found that higher numbers of active LMW-GS genes at the Glu-A3 and Glu-D3 loci in Xiaoyan 54 tended to produce greater ZSVs, an important indicator of breadmaking quality [16]. Similarly, the decrease in the number of active LMW-GS genes in CS-n due to deletion of the Glu-A3 locus likely contributed to the significant reduction in dough strength and breadmaking quality (Tables 2 and 3 ).

Wheat glutenin proteins generally display an up-regulated expression pattern during grain development (Figure 7a). Coordinated accumulation of transcripts from HMW-GS and LMW-GS genes, as well as $\alpha-, \gamma^{-}$, and $\omega$-gliadin genes, occurs early in grain development [54,57]. LMW-GS, HMW-GS, and $\omega$-gliadins can be detected by gel electrophoresis as early as 7 DPA [54], and 1018 DPA represents the key stage of storage protein synthesis [58]. In the present study, Glu-A3a transcripts demonstrated an updown expression pattern during grain development, and the highest expression level occurred at 14 DPA (Figure 7a), similar to a previous report [59]. SDS-PAGE analysis revealed that the Glu-A3a-encoded B-subunit displayed an up-regulated expression pattern and showed rapid synthesis and accumulation at 1117 DPA (Figure 7b), which is also generally in agreement with a previous report [55]. Thus, the Glu-A3a-encoded B-subunit has a higher accumulation rate during grain development similar to HMW-GS $5+10$ [54], which could improve the conformation of the regular gluten structure. Some important genes related to storage protein folding and synthesis, such as protein disulfide isomerase (PDI) and binding protein (BiP) genes, generally have higher expression levels at the early grain developmental stages. For instance, the PDI genes PDIL1-1 and PDIL2-1, which are involved in disulfide bond formation, displayed a peak expression level in the early stages (about 1015 DPA) of grain development [58]. The higher accumulation rate of the Glu-A3a-encoded B-subunit was accompanied by higher expression levels of the genes involved in storage protein synthesis and assembly during early grain development, suggesting that this subunit could improve the conformation of gluten macropolymers (GMP) and result in superior dough quality.

\section{Potential application of Glu-A3a in wheat quality improvement through molecular marker-assisted selection}

Characterization of the allelic variations of LMW-GS is important for improvement of wheat-processing quality. Some allelic variations of LMW-GS have greater positive effects on dough properties than others [3,45,60]. Marker-assisted selection is an effective supplement to conventional breeding practices. For LMW-GS, because of the low resolution of traditional SDS-PAGE and the tedious operation procedures involved in 2-DE, development of different markers is important for the study and application of target subunits.

Recently, with increasing numbers of LMW-GS alleles being cloned and sequenced from common wheat, different molecular markers have been developed to rapidly screen and select desirable Glu-3 alleles. Zhang et al. [41] developed a set of markers that can be used to discriminate the alleles Glu-A3a, $b, c, d, e, f$, and $g$. Long et al. [61] classified 69 LMW-GS genes registered in GenBank into nine groups and established nine groupspecific primer sets to identify each group. Ikeda et al. [62] developed 12 specific PCR markers to distinguish 12 groups of LMW-GS genes in the wheat cultivar Norin 61. Ten allele-specific STS markers for Glu-D3 were developed by Zhao et al. $[43,63,64]$. Wang et al. [35] designed 10 allele-specific PCR markers for the Glu-B3 locus based on SNPs present in the sequences of different allelic variants. Wang et al. [24] reported an allele-specific marker for Glu-A3b, which was not reported by Zhang et al. [41].

In the present study, we developed a new allele-specific PCR marker that can effectively discriminate Glu-A3a from other $G l u-A 3$ alleles, which was validated using different cultivars, including RILs and NILs (Figure $8 \mathrm{~b}$ ). This Glu-A3a allele-specific marker can be used in markerassisted breeding strategies aimed at the improvement of wheat quality. With help of this marker, it will be very convenient and effective for breeders to select this superior gene in early hybrid generations of a wheat quality program. However, this marker can only identify one specific gene in different generations and materials one time. The multiplex PCR systems showed to be more rapid and economic in identifying different desirable genes [24]. Thus, to improve the selection efficiency, it is needed to further develop multiplex PCR markers that can rapidly identify different desirable genes, including $G l u-A 3 a$ and other quality-related genes.

\section{Conclusions}

In the present study, we carried out the first molecular characterization and functional analysis of the properties of the Glu-A3a allele by using a Glu-A3 deletion line of the CS wheat variety (CS-n). The deletion of Glu-A3a 
had no clear effects on plant morphological and yield traits, but significantly reduced gluten strength and breadmaking quality. Molecular characterization revealed that Glu-A3a contains 1134 bp encoding one LMW-i type Bsubunit that had longer repetitive domains, an increased number of $\alpha$-helices, and showed a higher expression level and accumulation rate during grain development. These features could explain its major role in the formation of dough strength and breadmaking quality and indicate its potential value for wheat quality improvement. A specific AS-PCR marker for the Glu-A3a allele was developed and validated using different bread wheat cultivars, NILs, and RILs, which could be used as an effective molecular marker for gluten quality improvement through markerassisted selection.

\section{Method}

\section{Plant materials}

Chinese Spring (Triticum aestivum L., $2 \mathrm{n}=6 \mathrm{x}=42$, AABBDD) and its Glu-A3a deletion line (CS-n) developed in our laboratory were used in this study. AroonaA3a (Glu-A3a) and its six NILs: Aroona-A3b (Glu-A3b), Aroona $(G l u-A 3 c)$, Aroona-A3d (Glu-A3d), Aroona-A3e (Glu-A3e), Aroona-A3f (Glu-A3f), and Glenlea (Glu$A 3 g$ ) were used for identifying Glu-A3 alleles, which were kindly provided by Dr. Xianchun Xia, Institute for Crop Science, Chinese Academy of Agricultural Science (CAAS). Bread wheat cultivars CB037A, Chinese Spring substitution line CS-1S $/ 1 B$ [58], Chinese Spring $1 S^{1}$ genome addition line, and four recombination inbred lines (RILs) produced by crossing between CB037A and Chinese Spring substitution line CS- $1 S^{\mathrm{l}} / 1 \mathrm{~B}$ were used for identifying Glu-A3a deletion in CS-n, and developing and validating AS-PCR marker for Glu-A3a. All materials used in this study were listed in Additional file 10: Table S3.

\section{Identification of seed proteins Protein extraction, A-PAGE, SDS-PAGE and RP-UPLC}

According to the solubility in a series of solvents, grain albumins, globulins, gliadins and glutenins were extracted according to the established methods $[65,66]$.

\section{A-PAGE}

A-PAGE was conducted based on the method of Yan et al. $[66,67]$.

\section{SDS-PAGE}

SDA-PAGE was performed with Bio-Rad PROTEAN II $\mathrm{XL}$ equipment based on the previously described method [68] with $12 \%$ gel and electrophoresed at $15 \mathrm{~mA}$ for $2 \mathrm{~h}$.

\section{RP-UPLC}

RP-UPLC was used to separate HNW-GS and LMW-GS based on the recent reports [56,69]. The samples were performed on an Agilent 1100 using a Zorbax 300SBC18 column (300 A pore size and $5 \mathrm{~mm}$ particle size).

\section{MALDI-TOF-MS}

MALDI-TOF-MS was used to detect the accurate molecular weight (MW) of LMW-GS according to the previous reported method [39,70]. Shimadzu corporation AXIMA-CFRTM Plus MS apparatus (Japan) and the matrix of sinapinic acid (SA, a-cyano-4-hydroxycinnamic acid) were used.

\section{2-DE (IEF X SDS-PAGE)}

Grain glutenins and heterologously expressed LMW-GS were separated and identified by 2-DE (IEF SDSPAGE). The first dimension was performed by an EttanTM IPG-phor II TM system (GE Healthcare, USA) using $18 \mathrm{~cm}$ strips ( $\mathrm{pH} 6$ 11). The IEF rehydration solution was $7 \mathrm{M}$ urea, $2 \mathrm{M}$ thiourea and $4 \% \mathrm{CHAPS}$. The rehydrate condition was $30 \mathrm{~V}$ at $20 \mathrm{C}$ for $12 \mathrm{~h}$ while the IEF condition was $300 \mathrm{~V}$ for $1 \mathrm{~h}, 500 \mathrm{~V}$ for $1 \mathrm{~h}, 1000 \mathrm{~V}$ for $1 \mathrm{~h}, 3000 \mathrm{~V}$ for $1 \mathrm{~h}$, and $8000 \mathrm{~V}$ to $80,000 \mathrm{~V}$ for $10 \mathrm{~h}$. The second dimension was performed on a $12 \%$ acrylamide gradient. After electrophoresis, the 2-DE gels were stained with colloidal Coomassie Brilliant blue (CBB) (R-250/G-250 $=4: 1)$ and analyzed by using ImageMaster 2-D platinum software version 5.0 (Amersham Bioscience, Swiss Institute of Bioinformatics, Geneva, Switzerland, 2003) based on Lv et al. [71] with minor modifications. Three biological replicates were performed.

\section{LC-MS/MS}

The grain native and heterologous expressed LMW-GS separated by SDS-PAGE and 2-DE were further identified by LC-MS/MS. The expected LMW-GS band on the SDS-PAGE gel and 2-DE spots were excised and digested with trypsin according to Jin et al. [72]. The digested protein $(0.5 \mathrm{ml})$ was subject to MS analysis in a Waters SYNAPT High Definition Mass Spectromet ry (HDMS) mass spectrometer. The software BioworksBrowser 3.3 was used to analyze the LC-MS/MS data.

\section{Gluten quality testing}

Both CS and its CS-n were planted in Beijing experimental station of Chinese Academy of Agricultural Sciences during 20132014 growing season. The field design was three replications and each blot was $20 \mathrm{~m}^{2}$. Gluten quality parameters were tested according to Sun et al. [73] at Academy of State Administration of Grain. Flour moisture and ash contents (\% dry basis) were determined according to the American Association of Cereal Chemists Approved Methods (2000) 44-15A and 
08 02, respectively. Protein content (\%N 5.7, 14\% moisture basis) was determined by nitrogen combustion analysis with a LECO (Model FP analyzer, St. Jopeph, MI) calibrated against EDTA.

Farinograph parameters were obtained by using $10 \mathrm{~g}$ Brabender Farinograh-E based on American Association of Cereal Chemists Approved Method (2000) 5421.

Image analysis of crumb grain of bread was performed with a C-Cell, image analysing software and equipment (Calibre Control International Ltd.). Slice brightness and cell contrast were used to describe the brightness of slices. Number of cells, wall thickness, cell diameter, cell volume, coarse cell volume and average cell elongation were used to measure the cell properties. The sliced samples for textural analysis were prepared in the same way as those for the C-Cell.

\section{DNA extraction and PCR amplification}

Total genomic DNA from dry seeds was extracted according to McDonald et al. [74] and An et al. [39] with minor modifications. A pair of AS-PCR primers (A3-F and A3-R) was designed to amplify the coding regions of LMW glutenin gene based on the previously cloned sequences [13,24]. The primer sequences were A3-F: 5-GCCTTTCTTGT TTACGGCTG-3, A3-R: 5 -TCAGATTG ACATCCACAC AAT-3 (synthesized by Sangong Inc., China). PCR amplifications were performed in $50 \mu \mathrm{l}$ reaction volumes containing $2.5 \mathrm{U}$ La Taq polymerase (TaKaRa), $100 \mathrm{ng}$ of templet DNA, $25 \mathrm{ml}$ of $2 \mathrm{GC}$ buffer I ( $\mathrm{MgCl}_{2}^{+}$plus), $0.4 \mathrm{mM}$ dNTP, $0.5 \mu \mathrm{M}$ of each primer, and double distilled $\mathrm{H}_{2} \mathrm{O}$ added to $50 \mu \mathrm{l}$. The reactions were carried out in a PTC100 (MJ Research, Watertown, MA, USA) thermocycler using the following protocol: $94 \mathrm{C}$ for $2 \mathrm{~min}$, followed by 35 cycles of $94 \mathrm{C}$ for $45 \mathrm{~s}, 58 \mathrm{C}$ for $70 \mathrm{~s}$ and $72 \mathrm{C}$ for $2 \mathrm{~min}$, finally extended at $72 \mathrm{C}$ for $10 \mathrm{~min}$.

\section{Molecular cloning, DNA sequencing and sequences alignment}

PCR products were separated on $1.2 \%$ agarose gels in Tris acetic acid EDTA buffer and expected fragments were purified from the gels using a Quick DNA extraction kit (Tiangen, Beijng, China). Subsequently, purified products were ligated into a PMD18 T Easy vector (TaKaRa, Dalian, China) and transformed into cells of $E$. coli strain DH5 $\alpha$ according to Li et al. [75]. DNA sequencing was performed with three clones by Sino Geno Max, Beijing, China. Multiple sequence alignment of LMW glutenin nucleotide and protein sequences were completed by Bioedit 7.0.1.1.

\section{SNPs and InDels identification and secondary structure prediction}

Identification of SNPs and InDels present in LMW glutenin genes were based on multiple alignments and performed using Bioedit 7.0. Prediction of secondary structure of deduced amino acid sequences was carried out by PSIPRED server (http://bioinf.cs.ucl.ac.uk/psipred/) [34].

\section{Phylogenetic analysis}

MEGA 5 was used to construct a phylogenetic tree with the complete coding regions. Neighbor joining with Kimura two parameter correction methods and bootstrapping of 1,000 replicates were selected as working parameters [34,39,76-78].

\section{Expression of the cloned LMW-GS gene in E. coli}

The gene cloned was re-amplified to remove the signal peptides by designing a new pair of primers CS-F (5 GGGCATATGATTTCACAGCAACAA-3) and CS-R (5 -CTCGAGTCAGTAGACACCAACTCCGATG-3), NdeI and Xhol sites (underlined) were incorporated into the 5 ends of the CS-F and CS-R, respectively. After purification, the $\mathrm{PCR}$ products were ligated into the expression vector $\mathrm{pET}-30 \mathrm{a}$ (Novagen), and transformed into E.coli BL21 (DE3) plysS cells. And then we extract and separate the expressed protein from the E.coli, after that, we carried out them by SDS PAGE according to $\mathrm{Li}$ et al. [75].

\section{mRNA extraction, cDNA synthesis and qRT-PCR}

Developmental seeds from three spikes were combined together to extract total RNA from endosperm of CS and CS-n, and cDNA synthesis, qRT-PCR were according to Wang et al. [56]. The primers were: LMW-i-F: TGAAGACCTTCCTCGTCTTTG, LMW-i-R: CTGTGAAATT TGCGCAACG. Gene-specific primers were designed using Primer 5.0 and their specificities were checked by the melting curves of the RT-PCR products. Each qRTPCR reaction was performed in $20 \mu$ l volumes containing $10 \mu \mathrm{l} 2$ SYBR Premix Ex Taq (TaKaRa), $2 \mu \mathrm{l}$ 50-fold diluted cDNA, $0.4 \mu \mathrm{l}$ of each gene-specific primer and $7.2 \mu \mathrm{l}$ ddH2O. PCR conditions were as follows: $95 \mathrm{C}$ for $3 \mathrm{~min}$, 45 cycles of $15 \mathrm{~s}$ at $95 \mathrm{C}, 57 \mathrm{C}$ for $20 \mathrm{~s}$ and $72 \mathrm{C}$ for $20 \mathrm{~s}$.

Three replicates were used for each sample. Reactions were conducted in a CFX96 Real-Time PCR Detection System (Bio-Rad). All data were analyzed with CFX Manager Software (Bio-Rad).

\section{Determination of Glu-A3a deletion in CS by STS-PCR marker}

To identify the deletion of Glu-A3a in CS-n, we did the STS-PCR marker of the seven NILs, CS- $1 S^{1} / 1 B, S$ genome addition line, CB037A, CS, CS-n. We used the marker name of glu-A3a to do PCR as what Wang et al. [24] did before. The primer sets are LA1F: AAACAGAATTATTAAAGCCGG, and SA1R: GGTTGTTGTTGTTGCAG CA. Their PCR cycling conditions were $94 \mathrm{C}$ for $4 \mathrm{~min}$, 
followed by 35 cycles of $94 \mathrm{C}$ for $35 \mathrm{~s}, 55 \mathrm{C}$ for $45 \mathrm{~s}, 72 \mathrm{C}$ for $40 \mathrm{~s}$, and a final extension at $72 \mathrm{C}$ for $8 \mathrm{~min}$.

\section{Development and validation of allele-specific PCR markers for Glu-A3a}

To identify the Glu-A3a gene in different genotypes, based on the SNPs we detected in Glu-A3a, we designed the primer named Glu-A3a F: GCAAAGAAGGAAAAGAG GTGG, R: GGTTGTTGTTGTTGCTGCA as the primer to discriminate the gene Glu-A3a from others in CS and CS-n, this also validated in four RILs (CB037A and $\left.1 \mathrm{~S}^{\mathrm{l}} / 1 \mathrm{~B}\right)$, CS-1S $/ 1 \mathrm{~B}, 1 \mathrm{~S}^{\mathrm{l}}$ genome addition line, 7 NILs of Aroona and 48 varieties. PCR cycling conditions were $94 \mathrm{C}$ for $4 \mathrm{~min}$, followed by 35 cycles of $94 \mathrm{C}$ for $35 \mathrm{~s}, 60 \mathrm{C}$ for $30 \mathrm{~s}, 72 \mathrm{C}$ for $30 \mathrm{~s}$, and a final extension at $72 \mathrm{C}$ for $8 \mathrm{~min}$.

\section{Additional files}

Additional file 1: Figure S1. Plant, Spikelet and seeds morphology of CS and CS-n. A: Plant morphology of CS and CS-n. B1 and B2 are Spikelet morphology of CS and CS-n, respectively. C1 and C2 are the seeds of CS and CS-n, separately.

Additional file 2: Figure S2. Kernel morphology of different developmental times of CS and CS-n. The seeds are 5, 8, 11, 14, 17, 20, $23,26,29$ DPAs from CS and CS-n respectively. The characterization of them is similar.

Additional file 3: Table S1. Comparison of data statistics about the two varieties (CS and CS-n). We statistics plant height, Ear length, stronger spikelet number, kernels per spike, grain weight per spike, Tiller number and thousand kernel weight (TKW) of CS, CS-n.

Additional file 4: Figure S3. The comparison of the albumins, globulins and prolamins in CS and CS-n. 1 and 2 are the albumins of CS-n and CS, respectively. 3 is the globulins of CS-n, 4 is the globulins of CS. 5 and 6 are the prolamins of CS-n and CS, separately. The difference between them was marked by a black arrow.

Additional file 5: Figure S4. Identification of Glu-A3a in LMW-GS deletion lines of CS and CS-n by MALDI-TOF MS. The LMW-GS Glu-A3a is marked by a black arrow.

Additional file 6: Figure S5. Agarose gel electrophoresis separation of amplified products from genomic DNA of CS. With the AS-PCR primer, a single band was cloned in CS. Lane1 and Lane2: PCR amplified products and Lane3: 1 kb DNA marker.

Additional file 7: Figure S6. Sequence alignment of STS-PCR marker products of CS, Glu-A3a and its CDS. Glu-A3a is the full sequence, and the Glu-A3a CDS is the coding area. Marker is the band we cloned with the marker named glu-A3a from CS.

Additional file 8: Table S2. Comparison of the mature protein sequences of different LMW-i glutenin subunits. The number and positions of cysteine in different LMW-i glutenin subunits are different and relative conservative.

Additional file 9: Figure S7. aRT-PCR optimization design: double standard curve and dissolution curve of the gene Glu-A3a. The red standard curve represented G/u-A3a gene and the other blue standard curve represented the reference gene. The dissolution curves of different genes were indicated.

Additional file 10: Table S3. Validation of the Glu-A3a allele-specific markers with different wheat varieties, a set of NILs and 4 RILs. The source and the allele that contained were listed in this file.

\section{Abbreviations}

2D-PAGE: Two-dimensional gel electrophoresis (IEF SDS-PAGE); A-

PAGE: Acid polyacrylamide gel electrophoresis; AS-PCR: Allele specific- polymerase chain reaction; BAC: Bacterial artificial chromosome; BIP: Binding protein; CAAS: Chinese Academy of Agricultural Sciences; CBB: Coomassie brilliant blue; DPA: Days post anthesis; GMP: Glutenin macropolymer; HMWGS: High-molecular-weight glutenin subunits; InDels: Insertions/deletions; LCMS/MS: Liquid chromatography-mass spectrometer/mass spectrometer; LMW-GS: Low-molecular-weight glutenin subunits; MALDI-TOF MS: Matrixassisted laser desorption/ionization time-of-flight mass spectrometry; MCC: Micro-core collections; NILs: Near-isogenetic lines; ORFs: Open reading frame; PDI: Protein disulfide isomerase; PCR: Polymerase chain reaction; qRTPCR: Quantitative real-time polymerase chain reaction; RIL: Recombinant inbred line; RP-UPLC: Reversed-phase ultra performance liquid chromatography; Rmax: Extensograph maximum resistance; RWCN: Raw white Chinese noodle; SNPs: Single nucleotide polymorphisms; STSPCR: Sequence-tagged site polymerase chain reaction; SDS-PAGE: Sodium dodecyl sulphate-polyacrylamide gel electrophoresis; ZSV: Zeleny sedimentation value.

\section{Competing interests}

The authors declare that they have no competing interests.

\section{Authors contributions}

$\mathrm{ZS}, \mathrm{HC}$ and MC carried out all experiments and data analysis. GA, SX, ZM and LX performed the preparation of DNA, RNA, CDNA, PCR, GRT-PCR and 2-D. YY conceived the study, planned experiments, and helped draft the manuscript. All authors read and approved the final manuscript.

\section{Acknowledgements}

This research was financially supported by grants from the National Natural Science Foundation of China (31271703, 31471485), International Science \& Technology Cooperation Program of China (2013DFG30530), the National Key Project for Transgenic Crops in China (2014ZX08009-003), Natural Science Foundation of Beijing City and the Key Developmental Project of Science Technology, Beijing Municipal Commission of Education (KZ201410028031).

Received: 17 September 2014 Accepted: 5 December 2014 Published online: 19 December 2014

\section{References}

1. Shewry PR, Halford NG: Cereal seed storage proteins: structures, properties and role in grain utilization. J Exp Bot 2002, 53(370):947 958

2. Payne PI: Genetics of wheat storage proteins and the effect of allelic variation on bread-making quality. Annu Rev Plant Physiol 1987, 38(1):141 153.

3. Cornish G, Bekes F. Allen H, Martin D: Flour proteins linked to quality traits in an Australian doubled haploid wheat population. Crop Pasture Sci 2001, 52(12):1339 1348.

4. Jackson E, Holt L, Payne P: Characterisation of high molecular weight gliadin and low-molecular-weight glutenin subunits of wheat endosperm by two-dimensional electrophoresis and the chromosomal localisation of their controlling genes. Theor App/ Genet 1983, 66(1):29 37.

5. Yan Y, Prodanovic S, Mladenov N, Milovanovic M: Studies on genetic control of low-molecular-weight glutenin subunits in wheat endosperm by A-PAGE analysis. Cereal Res Comm 1999, 27(3):251 257.

6. D'Ovidio R, Masci S: The low-molecular-weight glutenin subunits of wheat gluten. J Cereal Sci 2004, 39(3):321 339.

7. Shewry P, Miflin B, LEW EJ, Kasarda D: The preparation and characterization of an aggregated gliadin fraction from wheat. J Exp Bot 1983, 34(11):1403 1410.

8. Lee Y-K, Ciaffi M, Appels R, Morell M: The low-molecular-weight glutenin subunit proteins of primitive wheats. II. The genes from A-genome species. Theor Appl Genet 1999, 98(1):126 134.

9. Kasarda D, Tao H, Evans P, Adalsteins A, Yuen S: Sequencing of protein from a single spot of a 2-D gel pattern: $\mathrm{N}$-terminal sequence of a major wheat LMW-glutenin subunit. J Exp Bot 1988, 39(7):899 906.

10. TAO HP, KASARDA DD: Two-dimensional gel mapping and N-terminal sequencing of LMW-glutenin subunits. J Exp Bot 1989, 40(9):1015 1020

11. Lew EJ-L, Kuzmicky D, Kasarda DD: Characterization of low molecular weight glutenin subunits by reversed-phase high-performance liquid chromatography, sodium dodecyl sulfate-polyacrylamide gel electrophoresis, and $\mathrm{N}$-terminal amino acid sequencing. Cereal Chem 1992, 69:508 508 
12. Pitts EG, Rafalski JA, Hedgcoth C: Nucleotide sequence and encoded amino acid sequence of a genomic gene region for a low molecular weight glutenin. Nucleic Acids Res 1988, 16(23):11376

13. Cloutier S, Rampitsch C, Penner GA, Lukow OM: Cloning and expression of a LMW-i glutenin gene. J Cereal Sci 2001, 33(2):143 154.

14. Ikeda $\mathrm{T}$, Nagamine $\mathrm{T}$, Fukuoka $\mathrm{H}$, Yano $\mathrm{H}$ : Identification of new low-molecular-weight glutenin subunit genes in wheat. Theor Appl Genet 2002, 104(4):680 687

15. Gupta R, Shepherd K: Two-step one-dimensional SDS-PAGE analysis of LMW subunits of glutelin. Theor App/ Genet 1990, 80(1):65 74

16. Dong L, Zhang X, Liu D, Fan H, Sun J, Zhang Z, Qin H, Li B, Hao S, Li Z, Wang $D$, Zhang $A$, Ling $H$ : New insights into the organization, recombination, and functional mechanism of low molecular weight glutenin subunit genes in bread wheat. PLoS One 2010, 5(10):e13548.

17. Zhang $X$, Jin H, Zhang Y, Liu D, Li G, Xia X, He Z, Zhang A: Composition and functional analysis of low-molecular-weight glutenin alleles with Aroona near-isogenic lines of bread wheat. BMC Plant Biol 2012, 12(1):243.

18. Zhang $X$, Liu D, Zhang J, Jiang W, Luo G, Yang W, Sun J, Tong Y, Cui D, Zhang A: Novel insights into the composition, variation, organization, and expression of the low-molecular-weight glutenin subunit gene family in common wheat. J Exp Bot 2013, 64(7):2027 2040

19. Pea R, Zarco-Hernandez J, Amaya-Celis A, Mujeeb-Kazi A: Relationships between chromosome 1B-encoded glutenin subunit compositions and bread-making quality characteristics of some durum wheat (Triticum turgidum) cultivars. J Cereal Sci 1994, 19(3):243 249.

20. Ito M, Fushie S, Maruyama-Funatsuki W, Ikeda TM, Nishio Z, Nagasawa K, Tabiki T, Yamauchi H: Effect of allelic variation in three glutenin loci on dough properties and bread-making qualities of winter wheat. Breed SCi 2011, 61(3):281 287.

21. Liu L, He ZH, Yan J, Zhang Y, Xia XC, Pena RJ: Allelic variation at the Glu-1 and Glu-3 loci, presence of the 1B.1R translocation, and their effects on mixographic properties in Chinese bread wheats. Euphytica 2005, 142(3):197 204

22. Meng XG, Xie F, Shang XW, An LZ: Association between allelic variations at the Glu-3 loci and wheat quality traits with Lanzhou Alkaline Stretched Noodles quality in northwest China spring wheats. Cereal Res Comm 2007, 35(1):109 118.

23. Jin H, Zhang Y, Li G, Mu P, Fan Z, Xia X, He Z: Effects of allelic variation of HMW-GS and LMW-GS on mixograph properties and Chinese noodle and steamed bread qualities in a set of Aroona near-isogenic wheat lines. J Cereal Sci 2013, 57:146 152

24. Wang L, Li G, Pea RJ, Xia X, He Z: Development of STS markers and establishment of multiplex PCR for Glu-A3 alleles in common wheat (Triticum aestivum L.). J Cereal Sci 2010, 51(3):305 312.

25. He Z, Yang J, Zhang Y, Quail K, Pena R: Pan bread and dry white Chinese noodle quality in Chinese winter wheats. Euphytica 2004, 139(3):257 267

26. Wieser $\mathrm{H}$, Kieffer $\mathrm{R}$ : Correlations of the amount of gluten protein types to the technological properties of wheat flours determined on a micro-scale. J Cereal Sci 2001, 34(1):19 27.

27. Cassidy B, Dvorak J, Anderson O: The wheat low-molecular-weight glutenin genes: characterization of six new genes and progress in understanding gene family structure. Theor App/ Genet 1998, 96(6 7):743 750

28. Johal J, Gianibelli M, Rahman S, Morell M, Gale K: Characterization of low-molecular-weight glutenin genes in Aegilops tauschii. Theor Appl Genet 2004, 109(5):1028 1040.

29. Li X, Wang A, Xiao Y, Yan Y, He Z, Appels R, Ma W, Hsam S, Zeller F: Cloning and characterization of a novel low molecular weight glutenin subunit gene at the Glu-A3 locus from wild emmer wheat (Triticum turgidum L. var. dicoccoides). Euphytica 2008, 159(1 2):181 190.

30. Masci S, D'Ovidio R, Lafiandra D, Kasarda DD: Characterization of a low-molecular-weight glutenin subunit gene from bread wheat and the corresponding protein that represents a major subunit of the glutenin polymer. Plant Physiol 1998, 118(4):1147 1158

31. D Ovidio R, Marchitelli C, Cardelli LE, Porceddu E: Sequence similarity between allelic Glu-B3 genes related to quality properties of durum wheat. Theor Appl Genet 1999, 98(3 4):455 461.

32. Gupta RB, Shepherd KW: Genetic Control of LMW Glutenin Subunits In Bread Wheat And Association With Physical Dough Properties. In Proceedings of the 3rd International Workshop on Gluten Proteins, Budapest, Hungary, May 9 12. Edited by Lasztity R, Bekes F. 1987.
33. Huang $X$, Cloutier S: Molecular characterization and genomic organization of low molecular weight glutenin subunit genes at the Glu-3 loci in hexaploid wheat (Triticum aestivum L.). Theor Appl Genet 2008, 116(7):953 966.

34. Wang K, Gao L, Wang S, Zhang Y, Li X, Zhang M, Xie Z, Yan Y, Belgard M, Ma W: Phylogenetic relationship of a new class of LMW-GS genes in the M genome of Aegilops comosa. Theor Appl Genet 2011, 122(7):1411 1425.

35. Wang LH, Zhao XL, He ZH, Ma W, Appels R, Pea RJ, Xia XC: Characterization of low-molecular-weight glutenin subunit Glu-B3 genes and development of STS markers in common wheat (Triticum aestivum L.). Theor App/ Genet 2009, 118:525 539.

36. Wang S, Li X, Wang K, Wang X, Li S, Zhang Y, Guo G, Hsam SLK, Zeller FJ, Yan $Y$ : Phylogenetic analysis of $C, U, N$ and $M$ genomes and their relationships with Triticum and other related genomes as revealed by LMW-GS genes at Glu-3 loci. Genome 2011, 54(4):273 284

37. Zhao H, Wang R, Guo A, Hu S, Sun G: Development of primers specific for LMW-GS genes located on chromosome 1D and molecular characterization of a gene from Glu-D3 complex locus in bread wheat. Hereditas 2004, 141(3):193 198

38. Jiang C, Pei Y, Zhang Y, Li X, Yao D, Yan Y, Ma W, Hsam S, Zeller F: Molecular cloning and characterization of four novel LMW glutenin subunit genes from Aegilops longissima, Triticum dicoccoides and $T$. zhukovskyi. Hereditas 2008, 145(2):92 98

39. An X, Zhang Q, Yan Y, Li Q, Zhang Y, Wang A, Pei Y, Tian J, Wang H, Hsam S: Cloning and molecular characterization of three novel LMW-i glutenin subunit genes from cultivated einkorn (Triticum monococcum L.). Theor App/ Genet 2006, 113(3):383 395.

40. Maruyama Funatsuki W, Takata K, Funatsuki H, Tabiki T, Ito M, Nishio Z, Kato A, Saito K, Yahata E, Saruyama H, Yamauchi H: Identification and characterization of a novel LMW-s glutenin gene of a Canadian Western Extra-Strong wheat. J Cereal Sci 2005, 41:47 57.

41. Zhang W, Gianibelli MC, Rampling LR, Gale KR: Characterisation and marker development for low molecular weight glutenin genes from Glu-A3 alleles of bread wheat (Triticum aestivum. L). Theor Appl Genet 2004, 108:1409 1419.

42. Johal J, Gianibelli MC, Rahman S, Morell MK, Gale KR: Characterization of low-molecular-weight glutenin genes in Aegilops tauschii. Theor Appl Genet 2004, 109:1028 1040

43. Zhao XL, Xia XC, He ZH, Lei ZS, Appels R, Yang Y, Sun QX, Ma WJ: Novel DNA variations to characterize low molecular weight glutenin Glu-D3 genes and develop STS markers in common wheat. Theor App/ Genet 2007, 114:451 460.

44. Huang Z, Long H, Wei YM, Yan ZH, Zheng YL: Molecular characterization of novel low-molecular-weight glutenin genes in Aegilops longissima. J App/ Genet 2010, 51(1):9 18

45. Gupta R, Singh N, Shepherd K: The cumulative effect of allelic variation in LMW and HMW glutenin subunits on dough properties in the progeny of two bread wheats. Theor Appl Genet 1989, 77(1):57 64 .

46. Harberd NP, Bartels D, Thompson RD: Analysis of the gliadin multigene loci in bread wheat using nullisomic-tetrasomic lines. Mol Gene Genet 1985, 198:234 242

47. Sabelli PA, Shewry PR: Characterization and organization of gene families at the Gli-1 loci of bread and durum wheats by restriction fragment analysis. Theor Appl Genet 1991, 83:209 216

48. Rasheed A, Xia X, Yan Y, Appels R, Mahmood T, He Z: Wheat seed storage proteins: Advances in molecular genetics, diversity and breeding applications. J Cereal Sci 2014, 60:11 24

49. Masci S, D ovidio R, Lafiandra D, Kasarda D: A 1B-coded low-molecularweight glutenin subunit associated with quality in durum wheats shows strong similarity to a subunit present in some bread wheat cultivars. Theor App/ Genet 2000, 100(3):396 400.

50. Tatham AS, Field JM, Smith SJ, Shewry PR: The conformations of wheat gluten proteins. II. Aggregated gliadins and low molecular weight subunits of glutenin. J Cereal Sci 1987, 51:203 214.

51. Tatham AS, Drake AF, Shewry PR: Conformational studies of synthetic peptides corresponding to the repetitive region of the high molecular weight (HMW) glutenin subunits of wheat. J Cereal Sci 1990, 11:189 200

52. Wang K, An X, Pan L, Dong K, Gao L, Wang S, Xie Z, Zhang Z, Appels R, Ma W, Yan Y: Molecular characterization of HMW-GS $1 D \times 3^{t}$ and $1 D \times 4^{t}$ genes from Aegilops tauschii and their potential value for wheat quality improvement. Hereditas 2012, 149:41 49. 
53. Butow B, Ma W, Gale K, Cornish G, Rampling L, Larroque O, Morell M, Bks F: Molecular discrimination of Bx7 alleles demonstrates that a highly expressed high-molecular-weight glutenin allele has a major impact on wheat flour dough strength. Theor App/ Genet 2003, 107(8):1524 1532.

54. Gupta RB, Masci S, Lafiandra D, Bariana HS, MacRitchie F: Accumulation of protein subunits and their polymers in developing grains of hexaploid wheats. J Exp Bot 1996, 47(9):1377 1385

55. Liu W, Zhang Y, Gao X, Wang K, Wang S, Zhang Y, He Z, Ma W, Yan Y: Comparative proteome analysis of glutenin synthesis and accumulation in developing grains between superior and poor quality bread wheat cultivars. J Sci Food Agri 2012, 92:106 115.

56. Li J, Han C, Zhen S, Li X, Yan Y: Characterization of HMW glutenin subunit $\mathrm{B} \times 7^{\mathrm{OE}}$ and its distribution in common wheat and related species. Plant Genetic Res: Characterization and Utilization 2014, 12(2):191 198.

57. Dupont F, Altenbach S: Molecular and biochemical impacts of environmental factors on wheat grain development and protein synthesis. J Cereal Sci 2003, 38(2):133 146.

58. Wang S, Yu Z, Cao M, Shen X, Li N, Li X, Ma W, Weigerber H, Zeller F, Hsam S: Molecular mechanisms of HMW glutenin subunits from $1 S^{\prime}$ genome of Aegilops longissima positively affecting wheat breadmaking quality. PLoS One 2013, 8(4):e58947.

59. Li X, Wang K, Wang S, Gao L, Xie X, Hsam SLK, Zeller FJ, Yan Y: Molecular characterization and comparative transcript analysis of two subclasses among LMW-m type genes from Aegilops species and bread wheat (Triticum aestivum L.). Theor App/ Genet 2010, 121:845 856.

60. Andrews JL, Hay RL, Skerritt JH, Sutton KH: HPLC and immunoassay-based glutenin subunit analysis: screening for dough properties in wheats grown under different environmental conditions. J Cereal Sci 1994 20:203 215

61. Long H, Wei YM, Yan ZH, Baum B, Nevo E, Zhen YL: Classification of wheat low-molecular-weight glutenin subunit genes and its chromosome assignment by developing LMW-GS group-specific primers. Theor Appl Genet 2005, 111:1251 1259.

62. Ikeda TM, Araki E, Fujita Y, Yano H: Characterization of low molecularweight glutenin subunit genes and their protein products in common wheats. Theor Appl Genet 2006, 112:327 334

63. Zhao XL, Ma W, Gale KR, Lei ZS, He ZH, Sun QX, Xia XC: Identification of SNPs and development of functional markers for LMW-GS genes at Glu-D3 and Glu-B3 loci in bread wheat (Triticum aestivum L.). Mol Breed 2007, 20:223 231

64. Zhao XL, Xia XC, He ZH, Gale KR, Lei ZS, Appels R, Ma WJ: Characterization of three low-molecular-weight Glu-D3 subunit genes in common wheat Theor Appl Genet 2006, 113:1247 1259.

65. Wang A, Gao L, Li X, Zhang Y, He Z, Xia X, Zhang Y, Yan Y: Characterization of two 1D-encoded $\omega$-gliadin subunits closely related to dough strength and pan bread-making quality in common wheat (Triticum aestivum L.). J Cereal Sci 2008, 47(3):528 535

66. Yan $Y$, Hsam S, Yu J, Jiang $Y$, Zeller F: Allelic variation of the HMW glutenin subunits in Aegilops tauschii accessions detected by sodium dodecyl sulphate (SDS-PAGE), acid polyacrylamide gel (A-PAGE) and capillary electrophoresis. Euphytica 2003, 130(3):377 385.

67. Yan Y, Jiang Y, Sun M, Yu J, Xiao Y, Zheng J, Hu Y, Cai M, Li Y, Hsam SL: Rapid identification of HMW glutenin subunits from different hexaploid wheat species by acidic capillary electrophoresis. Cereal Chem 2004, 81(5):561 566

68. Yan Y, Yu J, Jiang Y, Hu Y, Cai M, Hsam SL, Zeller FJ: Capillary electrophoresis separation of high molecular weight glutenin subunits in bread wheat (Triticum aestivum L.) and related species with phosphate-based buffers. Electrophoresis 2003, 24(9):1429 1436.

69. Yu Z, Han C, Yan X, Li X, Jiang G, Yan Y: Rapid characterization of wheat low molecular weight glutenin subunits by ultra performance liquid chromatography (UPLC). J Agric Food Chem 2013, 61(17):4026 4034

70. Pei Y, Wang A, An X, Li X, Zhang Y, Huang X, Yan Y: Characterization and comparative analysis of three low molecular weight glutenin C-subunit genes isolated from Aegilops tauschii. Can J Plant Sci 2007, 87(2):273 280

71. Lv D, Subburaj S, Cao M, Yan X, Li X, Appels R, Sun D, Ma W, Yan Y: Proteome and phosphoproteome reveals new response and defense mechanisms of Brachypodium distachyon leaves under salt stress. $\mathrm{Mol}$ Cell Proteomics 2013, 13(2):632 652
72. Jin M, Xie Z-Z, Ge P, Li J, Jiang S-S, Subburaj S, Li X-H, Zeller F-J, Hsam S-L-K, Yan Y-M: Identification and molecular characterisation of HMW glutenin subunit 1By16* in wild emmer. J App/ Genet 2012, 53(3):249 258

73. Sun H, Yan S, Jiang W, Li G, MacRitchie F: Contribution of lipid to physicochemical properties and Mantou-making quality of wheat flour. Food Chem 2010, 121(2):332 337.

74. McDonald M, Elliot $L$, Sweeney P: DNA extraction from dry seeds for RAPD analyses in varietal identification studies. Seed Sci Tech 1994, 22(1):171 176.

75. Li X, Zhang Y, Gao L, Wang A, Ji K, He Z, Appels R, Ma W, Yan Y: Molecular cloning, heterologous expression, and phylogenetic analysis of a novel y-type HMW glutenin subunit gene from the G genome of Triticum timopheevii. Genome 2007, 50(12):1130 1140.

76. Gaut BS, Morton BR, McCaig BC, Clegg MT: Substitution rate comparisons between grasses and palms: synonymous rate differences at the nuclear gene Adh parallel rate differences at the plastid gene rbcL. Proc Natl Acad Sci 1996, 93(19):10274 10279.

77. Kumar S, Tamura K, Nei M: MEGA3: integrated software for molecular evolutionary genetics analysis and sequence alignment. Brief Bioinformatics 2004, 5(2):150 163.

78. Zhang Y, Li Q, Yan Y, Zheng J, An X, Xiao Y, Wang A, Pei Y, Wang H, Hsam SL, Zeller FJ: Molecular characterization and phylogenetic analysis of a novel glutenin gene $\left(D y 10.1^{t}\right)$ from Aegilops tauschii. Genome 2006, 49(7):735 745

doi:10.1186/s12870-014-0367-3

Cite this article as: Zhen et al:: Deletion of the low-molecular-weight glutenin subunit allele Glu-A3a of wheat (Triticum aestivum L.) significantly reduces dough strength and breadmaking quality. $B M C$ Plant Biology 2014 14:367.

\section{Submit your next manuscript to BioMed Central and take full advantage of:}

$\otimes$ Convenient online submission

$\otimes$ Thorough peer review

$\otimes$ No space constraints or color $\nabla$ gure charges

$\nabla$ Immediate publication on acceptance

$\triangle$ Inclusion in PubMed, CAS, Scopus and Google Scholar

$\otimes$ Research which is freely available for redistribution

Submit your manuscript at www.biomedcentral.com/submit
C) Biomed Central 